\title{
CONCEITOS DE GEOPROCESSAMENTO PARA AUXILIAR PROFISSIONAIS DE ECOTURISMO
}

\author{
Aroldo Reis Vidal
}

José Wilson Corrêa Rosa

Monografia apresentada ao Centro de Excelência em Turismo da Universidade de Brasília como requisito parcial para obtenção do certificado de Especialista em Ecoturismo.

Brasília, DF, maio de 2003. 


$$
\begin{gathered}
\text { UNIVERSIDADE DE BRASíLIA } \\
\text { Centro de Excelência em Turismo } \\
\text { Curso de Especialização em Ecoturismo }
\end{gathered}
$$

\title{
CONCEITOS DE GEOPROCESSAMENTO PARA AUXILIAR PROFISSIONAIS DE ECOTURISMO
}

\author{
Aroldo Reis Vidal
}

Banca Examinadora

José Wilson Corrêa Rosa, PhD.

Orientador

Membro da Banca

Brasília, DF, 26 de maio de 2003. 
Catalogação na fonte elaborada pelo Bibliotecário Arlan Marcus de Lima. CRB1/1816.

Vidal, Aroldo Reis

Conceitos de geoprocessamento para auxiliar profissionais de ecoturismo / Aroldo Reis Vidal; José Wilson Corrêa Rosa. -- Brasília: UnB/CET, 2003.

xii, $70 f$ : : il. color.

Monografia (Especialização) -- Universidade de Brasília, Centro de Excelência em Turismo, 2003.

1. Turismo. 2. Ecoturismo 3. Meio-Ambiente. 4. Geoprocessamento.

I. Título. II. Rosa, José Wilson Corrêa. 


\section{Aroldo Reis Vidal}

Conceitos de Geoprocessamento para Auxiliar Profissionais de Ecoturismo

Comissão Avaliadora

José Wilson Corrêa Rosa

Professor(a)

Professor(a)

Brasília, DF, 26 de maio de 2003. 


\section{DEDICATÓRIA}

Dedico este trabalho àqueles que lutam pelas causas ambientais de preservação, aos Ecoturistas em especial, e àqueles que destinam seu tempo e conhecimento às pesquisas científicas relacionadas ao Geoprocessamento interligado ao Meio Ambiente e áreas correlatas.

Aos Professores que prestaram relevante dedicação e contribuição ao Curso, lembrando que o mesmo fora oferecido em caráter inaugural pelo Centro de Excelência em Turismo da UnB, contribuindo para sua realização bem como o desenvolvimento desta Monografia.

Dedicado também aos meus pais Luiz de Sousa Vidal e Maria da Conceição Reis Vidal, aos meus parentes, familiares e amigos que me apoiaram de forma incondicional na realização deste curso e atividades pertinentes.

Em especial e de forma carinhosa à minha esposa Adriana Prazeres Salgueiro que incentivou-me em todos os momentos, acreditando no meu conhecimento e capacidade, dando-me veemência, persistência, esperança e alegria para a conclusão dos trabalhos desta Especialização. 


\section{AGRADECIMENTOS}

Agradeço a Deus e a Sagrada Família por serem onipresentes à minha existência e tê-los como apoio e estímulo para qualquer caminhada.

Aos Professores e Mestres Carmélia Anna Amaral, Carlos Delphin, Marcelo Brito, Sérgio Salvati, Laís Mourão, Suzana Pádua, Jeanine Fagg, Humberto Ângelo, Sônia Wiedmann, Dóris Faria, Mônica Veríssimo, Fábio de Jesus, Lucila Egydio e especialmente à Manoel Cláudio pela dedicação e empenho ao 1ํㅡㄴ Curso de Pósgraduação Lato Senso em Ecoturismo da UnB.

Particularmente ao Professor José Wilson Corrêa Rosa que aceitou prontamente ser meu orientador, ajudando-me sobremaneira na elaboração desta Monografia, informando, esclarecendo, orientando e instruindo nas pesquisas necessárias para esta realização.

Não obstante, agradeço aos meus familiares, colegas de trabalho e amigos pessoais dentre os quais reservo-me o direito de destacar os nomes de companheiros solidários como Fabrício Vieira Cezar, por sempre motivar esta e novas empreitadas, e Edilene Betânia Brito pelos eventuais conselhos, esclarecimentos e assistências sempre prestados incondicionalmente. 


\section{EPÍGRAFE}

"Aqueles que estudam e se empenham para aprender estão constantemente crescendo e se desenvolvendo; seu coração é rico. Pessoas que continuamente procuram adquirir novos conhecimentos e compreensão são os verdadeiros vitoriosos na vida." 


\section{RESUMO}

O presente trabalho apresenta conceitos referentes ao Ecoturismo e ao Geoprocessamento tendo em vista a viabilização de um empreendimento ecoturístico eficaz e seguro, envolvendo trajetos, potencialidades, planejamento de trilhas, manejo e monitoramento, sustentabilidade e cultura das comunidades locais.

Considerando que o Geoprocessamento é a mais moderna e eficiente tecnologia para processamento de dados espaciais, com destaque nas aplicações de análises ambientais, de planejamento e gestão do território, zoneamentos, monitoramentos e em mapeamentos temáticos dos recursos naturais, e a enorme diversidade de imagens atualmente coletadas por satélite que possibilitam a observação da Terra e os diversos fenômenos que ocorrem na natureza, permitindo a construção detalhada de documentos cartográficos e/ou temáticos, que em Sistemas de Informações Geográficas (SIG), podem ser armazenados em meios digitais, atualizados periodicamente e integrados e combinados a outras fontes de dados, para se produzir informações de valor social, econômico e científico, observourse que a união do Ecoturismo e Geoprocessamento seria o procedimento adequado para o sucesso deste estudo.

Esta monografia descreve a importância das tecnologias de Geoprocessamento voltadas para o Ecoturismo, enfatizando possíveis aplicações que auxiliariam sua divulgação no Brasil e a preservação do meio ambiente. 


\section{ABSTRACT}

This work was carried out to introduce concepts regarding Ecotourism and Geoprocessing for the effectiveness of a safe and powerful ecotouristic enterprise. Such demands must involve safety, itineraries, potentialities, planning and handling of trails, sustainability and the local communities' culture.

Geoprocessing is a state of the art technology in the processing of spatial data applicable for environmental analyses, territory planning and management, zonings, investigations and natural resource thematic maps. A great variety of satellite images improve the observation of the Earth and it's many phenomenons. This makes possible the detailed construction of cartographic and/or thematic documents. Through Geographical Information Systems (GIS) data can be stored in digital means, updated periodically and integrated and combined into other sources of data, to produce valuable social, economic and scientific information. It was observed that the union of Ecotourism and Geoprocessing would be the appropriate procedure for the success of this study.

This study describes the importance of Geoprocessing technologies in Ecotourism activities and highlights it's possible uses to protect natural environments and also help to develop this practice in Brazil. 


\section{SUMÁRIO}

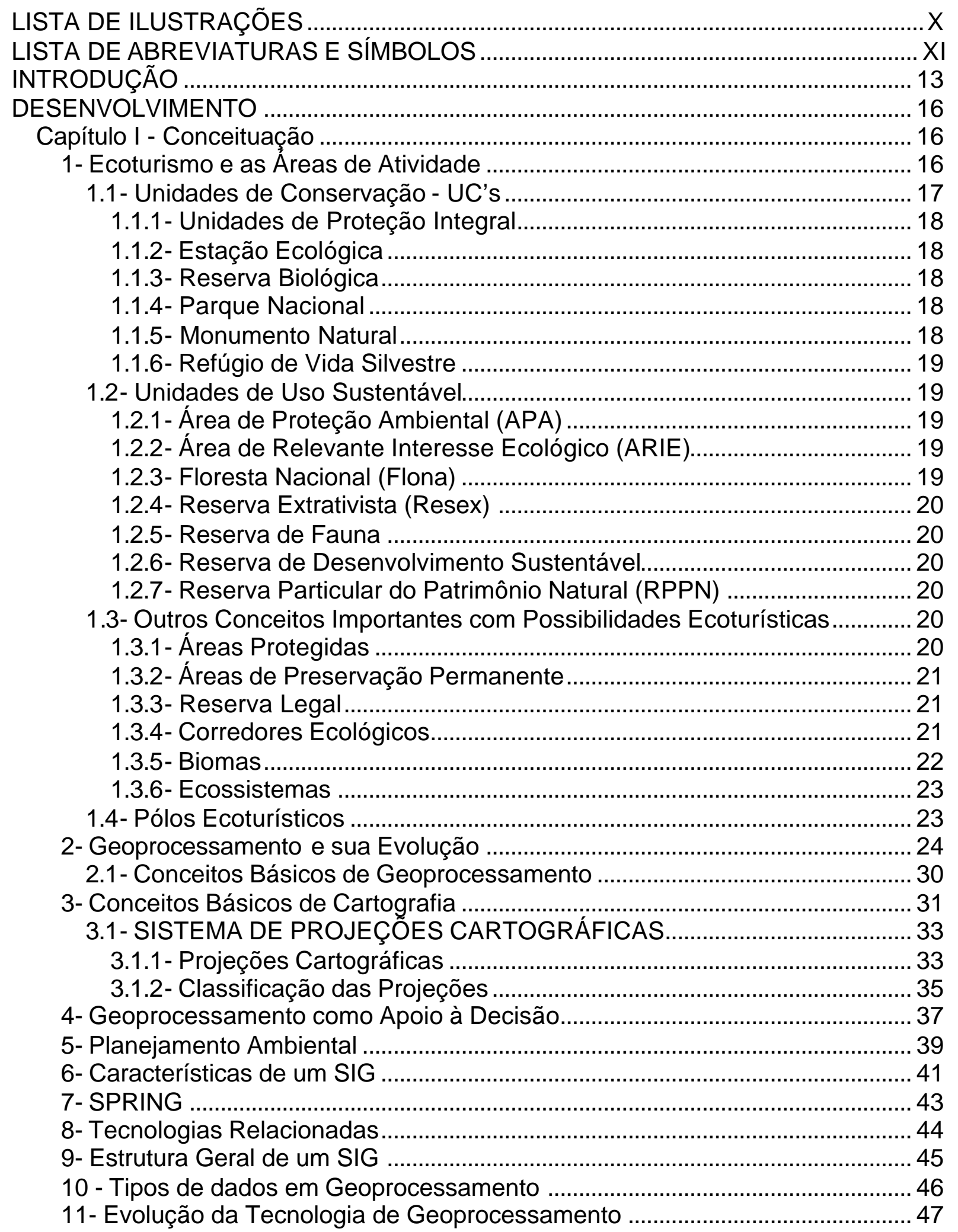


12- Origem e Evolução do Sensoriamento Remoto ................................................ 49

13- Definição de Sensoriamento Remoto .................................................................50

Capítulo II - Descrição da Metodologia da Pesquisa ................................................ 53

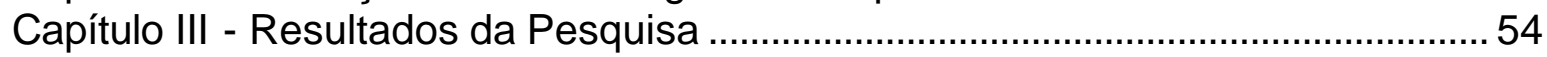

Capítulo IV - Discussão dos Resultados da Pesquisa ...............................................57

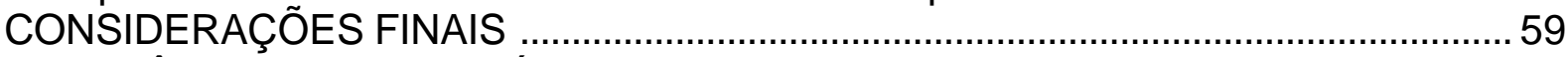

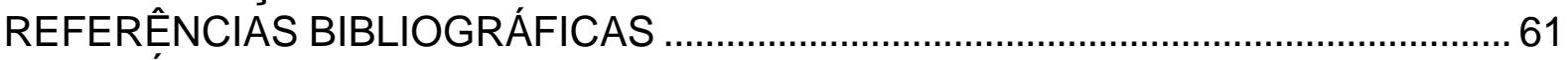

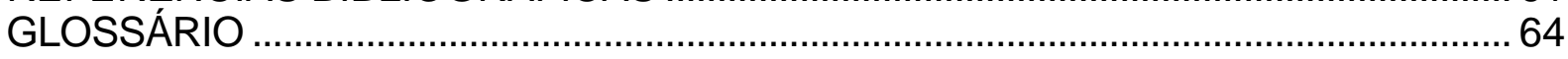




\section{LISTA DE ILUSTRAÇÕES}

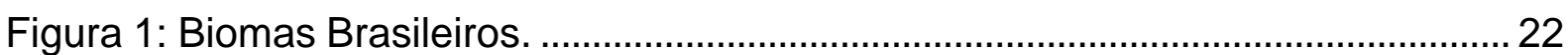

Figura 2: Mapa dos Pólos de Ecoturismo no Brasil. ……………………………......2 24

Figura 3: Arquitetura de Sistemas de Informação Geográfica. ..................................... 46

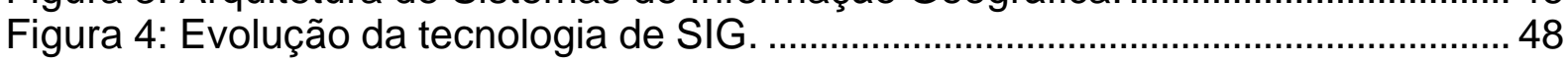

Figura 5: Trajetórias da Radiação...................................................................... 51

Quadro 1. Etapas e procedimentos metodológicos em planejamento ambiental. ..... 40 


\section{LISTA DE ABREVIATURAS E SÍMBOLOS}

AM/FM - Automated Mapping, ou mapeamento Automatizado, Facility Management: Gerenciamento de Serviços de Utilidade Pública.

APA - Área de Proteção Ambiental

ARIE - Área de Relevante Interesse Ecológico

CAD - Computer Aided Drafting: Desenho assistido ou auxiliado por computador. Abrange os programas com funções capazes de criar e ou modificar desenhos vetoriais.

CADD - Computer Aided Design and Drafting.

CAM - Computer Assisted Mapping.

CIG - Caderno de Informações Georreferenciadas

CPqD/TELEBRÁS - Centro de Pesquisa e Desenvolvimento da TELEBRÁS

CREAR - Centro de Referência de Educação Ambiental de Resende

CVRD - Companhia Vale do Rio Doce

EMBRATUR - Instituto Brasileiro de Turismo.

ESRI - Environmental Systems Research Institute: empresa dedicada exclusivamente à implementação e ao uso de mapas digitais e sistemas computadorizados de informações geográficas.

FEMA - Fundação Estadual do Meio Ambiente

FLONA - Floresta Nacional

FUNTAC - Fundação de Tecnologia do Acre

GEAN - Grupo Excursionista Agulhas Negras

GEEP - Grupo Ecológico de Engenheiro Passos

GEMPI - Gestão Empresarial \& Informática Ltda.

GIS - Geographic Information System / Sistema de Informação Geográfica (SIG).

GPS - Global Positioning System / Sistema de Posicionamento Global: Sistema criado para navegação, utilizando sinais emitidos por satélites artificiais. Suas 
aplicações incluem navegação e posicionamento no mar, no ar e sobre a superfície terrestre.

IBAMA - Instituto Brasileiro do Meio Ambiente e dos Recursos Naturais Renováveis

INPE - Instituto Nacional de Pesquisa Espacial

LIS - Land Information System: Sistema baseado no mesmo princípio do GIS, diferindo deste pelo fato do LIS abordar o mapeamento de fronteiras legais, propriedades, etc.

MMA - Ministério do Meio Ambiente

MRN - Mineração Rio do Norte

NCGIA - National Centre for Geographical Information and Analysis

ONG's - Órgãos Não Governamentais

PNMA - Política Nacional de Meio Ambiente

RESEX - Reserva Extrativista

RPPN - Reserva Particular do Patrimônio Natural

SAGA - Sistema de Análise Geo-Ambiental

SAGRE - Sistema Automatizado de Gerência da Rede Externa

SIG - Sistemas de Informações Geográficas / Geographic Information System (GIS).

SNUC - Sistema Nacional de Unidades de Conservação

SR - Sensoriamento remoto

UC's - Unidades de Conservação

UFRJ - Universidade Federal do Rio de Janeiro.

UnB - Universidade de Brasília.

UNIX - Sistema operacional desenvolvido originalmente para aplicações cientificas em grandes computadores, com uso crescente em micros. Permite a execução de várias tarefas simultâneas (sistema multitarefa). Ideal para aplicações multiusuárias.

UTM - Universal Transverse Mercator. 


\section{INTRODUÇÃO}

A preocupação com a preservação do meio ambiente é um fator evidente em diversos países, sejam os desenvolvidos, subdesenvolvidos ou em desenvolvimento. Questões como desemprego e de uma conscientização ecológica podem ser resolvidos com a entrada do Ecoturismo.

Considerando necessária a preservação do meio ambiente esta nova atividade embasada sob os conceitos de desenvolvimento sustentável e que, além de envolver lazer, aventura, saúde, prazer, relaxamento além de outros, proporciona a possibilidade real de gerar empregos para os diversos setores envolvidos, resultando em uma poderosa atividade econômica: O Ecoturismo.

Atividades ecoturísticas com 0 auxílio do Geoprocessamento oferece possibilidades e resultados satisfatórios já apresentados em algumas Unidades de Conservação (UC's) em muitos países pois, tanto o Ecoturismo quanto o Geoprocessamento, dadas as devidas proporções, são eficientes ferramentas de auxílio ao monitoramento de áreas preservadas e ecossistemas.

O presente trabalho objetiva analisar, sucintamente, as contribuições que as técnicas do Geoprocessamento podem oferecer para a implementação do Ecoturismo. Para isso buscoutse informações bibliográficas e documentais, coletando dados em livros, artigos, estudos teóricos, revistas científicas, internet e publicações de pesquisadores, empresas, instituições e órgãos governamentais como do Instituto Brasileiro do Meio Ambiente e dos Recursos Naturais Renováveis (IBAMA)/Ministério do Meio Ambiente (MMA), Instituto Nacional de Pesquisas Espaciais (INPE), Instituto Brasileiro de Geografia e Estatistica (IBGE), Conselho Nacional de Desenvolvimento Científico e Tecnológico (CNPq)/Ministério da Ciência e Tecnologia (MCT) e Instituto Brasileiro de Turismo (EMBRATUR). Contudo observourse que existe uma extensa bibliografia distintamente, entretanto são escassos os estudos que co-relacionam o Ecoturismo ao Geoprocessamento. 
Esta monografia agrupa de uma forma consciente conceitos de Ecoturismo e Geoprocessamento, buscando mostrar a eficiência que essa parceria pode beneficiar tanto a natureza quanto a humanidade.

Existe uma demanda crescente para o desenvolvimento de novas áreas voltadas ao Ecoturismo, assim como o manejo mais intensivo dos já existentes. Nesse caso, o uso do Geoprocessamento podem propiciar um inventário mais rápido, econômico e preciso. Problemas como detecção de caminhos ilegais dentro de grandes áreas, mudanças no uso de terra, compactação do solo em algumas áreas, inventários de rios e lagos, planejamento de construção de estradas e pontes, delimitação de áreas de interesses especiais.

Atualmente com a grande diversidade de sistemas sensores, especialmente com o Geoprocessamento que é definido como o conjunto de tecnologias de coleta, tratamento de informações espaciais e desenvolvimento de sistemas que as utilizam. As áreas que se servem das tecnologias de geoprocessamento têm em comum, o interesse por formas espaciais. Estes sistemas são mais comumentes tratados como Sistemas de Informações Geográficas (SIG's).

O SIG, tem como objetivo, elaborar um sistema que utilize a capacidade de gerenciamento de um banco de dados, de modo a realizar consultas e apresentar dados geográficos sob várias formas de apresentação que ajudem na investigação de tomada de decisões.

Como objetivos para a consecução dessas metas, o trabalho se propõe a:

- Analisar e revisar a literatura sobre técnicas de apresentação de dados geográficos dentro de um SIG;

- Propõe procedimentos para a implementação do ecoturismo auxiliado pelo geoprocesamento;

- Disponibilizar tais técnicas como exemplo de visualização de um SIG.

Um sistema de geoprocessamento pode ser tratado como tal, destinado ao processamento de dados referenciados geograficamente (ou georreferenciados), desde a sua coleta até a geração de saídas na forma de mapas convencionais, relatórios, arquivos digitais, etc; devendo prever recursos para sua estocagem, gerenciamento, manipulação e análise. 
Com a evolução da tecnologia de geoprocessamento e de softwares gráficos, vários termos surgiram para as várias especialidades. O nome Sistemas de Informação Geográfica (ou Geographic Information System - GIS) é muito utilizado e em muitos casos é confundido com geoprocessamento. O geoprocessamento é o conceito mais abrangente e representa qualquer tipo de processamento de dados georreferenciados, enquanto um SIG processa dados gráficos e não gráficos (alfanuméricos) com ênfase a análises espaciais e modelagens de superfícies.

Estas definições de SIG refletem, cada uma à sua maneira multiplicidade de uso e visões possíveis desta tecnologia e apontam para uma perspectiva interdisciplinar de sua utilização para o ecoturismo.

O sistema desenvolvido para divulgar o turismo são mapas digitalizados e scanerizados. Paisagens e pontos turísticos em forma digital, informações sobre turismo e, de posse destas, decidir para onde ir, o que visitar, onde ficar, como chegar, qual o melhor caminho e, ainda, como obter mais informações.

Como em qualquer outra atividade, seja ela econômica ou não, o Ecoturismo também necessita de planejamento e monitoramento para a obtenção dos resultados previstos e principalmente para que não haja um desgaste desordenado dos recursos naturais, seu principal produto. As tecnologias, que antes auxiliavam a espionagem da guerra fria, estão ligadas à Geociências, principalmente o Geoprocessamento, e tornaram-se poderosas ferramentas para o monitoramento e preservação da natureza, levantamento e análise de diferentes extratos vegetais e regiões de produção, definição de rotas eficientes para o sistema viário.

O simples deslocamento de um ponto a outro na superfície de nosso planeta, já justifica a necessidade de se visualizar de alguma forma as características físicas do "mundo". As variáveis visuais quantitativas (medidas, valor, textura) podem ser eficientes sobre mapas mostrando um ordenamento de características. Pontos que variam de tamanho ou medida são ideais para retratar quantidade ou magnitude. Símbolos de área que variam em valor ou gradação de cores também são desejáveis, porém menos efetivos. Textura é normalmente um símbolo de baixa resolução e não devem ser usada em superfícies muito pequenas, porque dificulta a codificação e debilita a transmissão da informação. 


\section{DESENVOLVIMENTO}

\section{Capítulo I - Conceituação}

\section{1- Ecoturismo e as Áreas de Atividade}

O ecoturismo surgiu na década de 80, e em agosto de 1994 um grupo multidisciplinar, ao analisar critérios para fins de implementar diretrizes para uma política nacional de ecoturismo, definiu: "Ecoturismo é um segmento da atividade turística que utiliza de forma sustentável o patrimônio natural e cultural, incentiva a sua conservação e busca a formação de uma consciência ambientalista através da interpretação e do ambiente, promovendo o bem estar das populações envolvidas."

O termo "ecotourism" ou ecoturismo é atribuído ao mexicano Hector Ceballos Lascurain, que deu uma primeira definição do conceito em 1983: "viajar para uma região relativamente selvagem com o objetivo específico de estudar, admirar e desfrutar da paisagem, plantas e animais, assim como das manifestações culturais existentes".

Cada vez mais pessoas, com vida mais longa, com mais tempo livre e com rendas familiares crescentes, com menos barreiras políticas e sociais, e com muito mais informação vão concretizando o desejo e algumas vezes o sonho de viajar, conhecer lugares novos, culturas novas, vidas novas e diferentes experiências daquelas que constituem sua rotina diária. Visitar áreas naturais relativamente pouco perturbadas para desfrutar, estudar ou voluntariar assistência é fazer turismo ecológico (BARROS, 1997).

Conforme Quintão (1990) o Ecoturismo deve ser entendido como atividade de laser, voltada para a valorização do ócio, em que o homem busca, por necessidade 
e direito, a revitalização da capacidade interativa e do prazer lúdico nas relações com a natureza. O tempo do ócio foi transformado pelo capital numa indústria, que apresenta o turista como mais uma opção de consumo da sociedade, na expectativa de obter retorno em lucro monetário.

É um turismo especializado, no qual o turista participa ativamente da viagem, fazendo, por exemplo, caminhadas, pesca esportiva e observação de animais silvestres e vegetações endêmicas e que, se corretamente planejado e monitorado, pode facilmente ser vinculado a um sistema educativo, possibilitando despertar o interesse dos visitantes e propagar informações básicas sobre o meio físico, que podem ser muito úteis inclusive para a gestão de problemas ambientais urbanos.

Devido à sua diversidade biológica e cênica, o Brasil destaca-se mundialmente como um dos mais ricos destinos do turismo ligado à natureza.

Esta vocação ambiental tem contribuído para o crescimento do interesse no país pelo Ecoturismo, devido à existência de diversificados e contrastantes ecossistemas como o Cerrado, a Mata Atlântica, o Pantanal, a Caatinga e a Floresta Amazônica.

Os ecossistemas citados anteriormente, encontram-se em determinadas regiões sob a responsabilidade e interesse comum ou privado. Muitas dessas regiões são conhecidas inclusive internacionalmente e atraem um grande número de visitantes; outras porém, são de difícil acesso ou se desconhece o seu potencial e vocação ecoturística, correndo o risco de serem desmatadas provocando mais um desastre ecológico.

Para a preservação e conservação dessas regiões, existem leis e órgãos específicos que, por intermédio de inúmeros atores envolvidos com as questões ambientais e que trabalham exaustivamente pela causa, auxiliam e protegem tais regiões, que são conhecidas como Unidades de Conservação (MMA, 2003).

\section{1- Unidades de Conservação - UC's}

São espaços territoriais (incluindo seus recursos ambientais e as águas 
jurisdicionais) com características naturais relevantes, legalmente instituídos pelo Poder Público, com objetivos de conservação e com limites definidos, sob regime especial de administração, às quais se aplicam com garantias adequadas de proteção.

\subsection{1- Unidades de Proteção Integral}

O objetivo básico dessas unidades é preservar a natureza, sendo admitido apenas o uso indireto dos seus recursos naturais, ou seja, atividades educacionais, científicas e recreativas.

Esse grupo dividi-se nas seguintes categorias de unidade de conservação:

\subsection{2- Estação Ecológica}

Tem como objetivo a preservação da natureza e a realização de pesquisas científicas. É de posse e domínio públicos.

\subsection{3- Reserva Biológica}

Tem como objetivo a proteção integral da biota e demais tributos naturais existentes em seus limites, sem interferência humana direta ou modificações ambientais, excetuando-se as medidas de recuperação de seus ecossistemas alterados e as ações de manejo necessárias para recuperar e preservar o equilíbrio natural, a diversidade biológica e os processos ecológicos naturais. É de posse e domínio públicos.

\subsection{4- Parque Nacional}

Tem como objetivo básico a preservação de ecossistemas naturais de grande relevância ecológica e beleza cênica, possibilitando a realização de pesquisas científicas e o desenvolvimento de atividades de educação e interpretação ambiental, de recreação em contato com a natureza e de turismo ecológico. É de posse e domínio públicos.

\subsection{5- Monumento Natural}

Tem como objetivo básico preservar sítios naturais raros, singulares ou de 
grande beleza cênica. Pode ser constituído por áreas particulares.

\subsection{6- Refúgio de Vida Silvestre}

Tem como objetivo proteger ambientes naturais onde se asseguram condições para a existência ou reprodução de espécies ou comunidades da flora local e da fauna residente ou migratória.

\section{2- Unidades de Uso Sustentável}

O objetivo básico dessas unidades é compatibilizar a conservação da natureza com o uso sustentável de parcela dos seus recursos naturais. Esse grupo é composto pelas seguintes categorias de unidades de conservação:

\subsection{1 - Área de Proteção Ambiental (APA)}

Área extensa, com certo grau de ocupação humana, dotada de atributos abióticos, bióticos, estéticos ou culturais especialmente importantes para a qualidade de vida e o bem-estar das populações humanas, e tem como objetivos básicos proteger a diversidade biológica, disciplinar o processo de ocupação e assegurar a sustentabilidade do uso dos recursos naturais. É constituída por terras públicas ou privadas.

\subsection{2- Área de Relevante Interesse Ecológico (ARIE)}

É uma área em geral de pequena extensão, com pouca ou nenhuma ocupação humana, com características naturais extraordinárias ou que abriga exemplares raros da biota regional, e tem como objetivo manter os ecossistemas naturais de importância regional ou local e regular o uso admissível dessas áreas, de modo a compatibilizá-lo com os objetivos de conservação da natureza. É constituída por terras públicas ou privadas.

\subsection{3- Floresta Nacional (Flona)}

É uma área com cobertura florestal de espécies predominantemente nativas e tem como objetivo básico o uso múltiplo sustentável dos recursos florestais e a 
pesquisa científica, com ênfase em métodos para exploração sustentável de florestas nativas. É de posse e domínio públicos.

\subsection{4- Reserva Extrativista (Resex)}

É uma área utilizada por populações extrativistas tradicionais, cuja subsistência baseia-se no extrativismo e, complementariamente, na agricultura de subsistência e na criação de animais de pequeno porte, e tem como objetivos básicos proteger os meios de vida e a cultura dessas populações, e assegurar o uso sustentável dos recursos naturais da unidade. É de domínio público com seu uso concedido às populações extrativistas tradicionais.

\subsection{5- Reserva de Fauna}

É uma área natural com populações animais de espécies nativas, terrestres ou aquáticas, residentes ou migratórias, adequadas para estudos técnico-científicos sobre manejo econômico sustentável de recursos faunísticos. É de posse e domínio públicos.

\subsection{6- Reserva de Desenvolvimento Sustentável}

É uma área natural que abriga populações tradicionais, cuja existência baseia-se em sistemas sustentáveis de exploração dos recursos naturais, desenvolvidos ao longo de gerações e adaptados às condições ecológicas locais e que desempenham um papel fundamental na proteção da natureza e na manutenção da diversidade biológica. É de domínio público.

\subsection{7- Reserva Particular do Patrimônio Natural (RPPN)}

É uma área privada, gravada com perpetuidade, com o objetivo de conservar a diversidade biológica.

\section{3- Outros Conceitos Importantes com Possibilidades Ecoturísticas}

\subsection{1 - Áreas Protegidas}

Áreas Protegidas são áreas de terra e/ou mar especialmente dedicadas à 
proteção e manutenção da diversidade biológica, e de seus recursos naturais e culturais associados, manejadas por meio de instrumentos legais ou outros meios efetivos.

\subsection{2- Áreas de Preservação Permanente}

Áreas de Preservação Permanente são definidas pelo Código Florestal como sendo certas áreas públicas, ou particulares, nas quais a supressão total ou parcial da vegetação natural só é permitida, mediante prévia autorização do Poder Executivo Federal, quando necessária a execução de obras, planos, atividades ou projetos de utilidade pública ou de interesse social. Como exemplo de áreas de preservação permanente podem ser citadas: as margens dos rios; ao redor de lagoas, lagos ou reservatórios d'água; e os topos de morros, montes, montanhas e serras. Por ato do Poder Público, outras áreas também podem ser definidas como de preservação permanente.

\subsection{3- Reserva Legal}

É a área de cada propriedade particular onde não é permitido o corte raso da cobertura vegetal. Essa área deve ter seu perímetro definido, sendo obrigatório sua averbação à margem da inscrição da matrícula do imóvel do registro de imóveis competente. Ainda que a área mude de titular ou seja desmembrada é vedada a alteração de sua destinação. Como prevê o Código Florestal, o percentual das propriedades a ser definido como reserva legal varia de acordo com as diferentes regiões do Brasil.

\subsection{4- Corredores Ecológicos}

O termo "corredores" foi primeiramente usado por Simpson (1963) no contexto de dispersão de fauna entre os continentes. Os registros paleontológicos são um "testamento" do valor de corredores intercontinentais. Hoje em dia, o enfoque dado a corredores para reservas naturais é bem diferente. Entretanto, é interessante especular o quanto a idéia foi influenciada pela percepção anterior de que a biota se dispersa ao longo dos vales, bacias hidrográficas e outras características fisiográficas (Shafer, 1990). Leopold (1949) notou que vários animais, por razões desconhecidas, não pareciam ater-se às suas populações, porém, foi 
Preston (1962) que recomendou o uso de corredores entre reservas. Usados estrategicamente, os corredores e zonas de amortecimento podem mudar fundamentalmente o papel ecológico das áreas protegidas. Esses corredores serviriam para aumentar o tamanho e as chances de sobrevivência de populações pequenas, além de poderem servir como possibilidades de recolonização de espécies localmente perdidas e, ainda, permitir a redução da pressão do entorno das áreas protegidas. (Ministério do Meio Ambiente)

\subsection{5- Biomas}

É uma área geográfica extensa, correspondendo às principais formações vegetais naturais. Os biomas brasileiros estão assim divididos: Amazônia, Caatinga, Cerrado / Pantanal, Mata Atlântica / Campos e Zona Costeira Marinha (Figura 1).

Figura 1: Biomas Brasileiros.

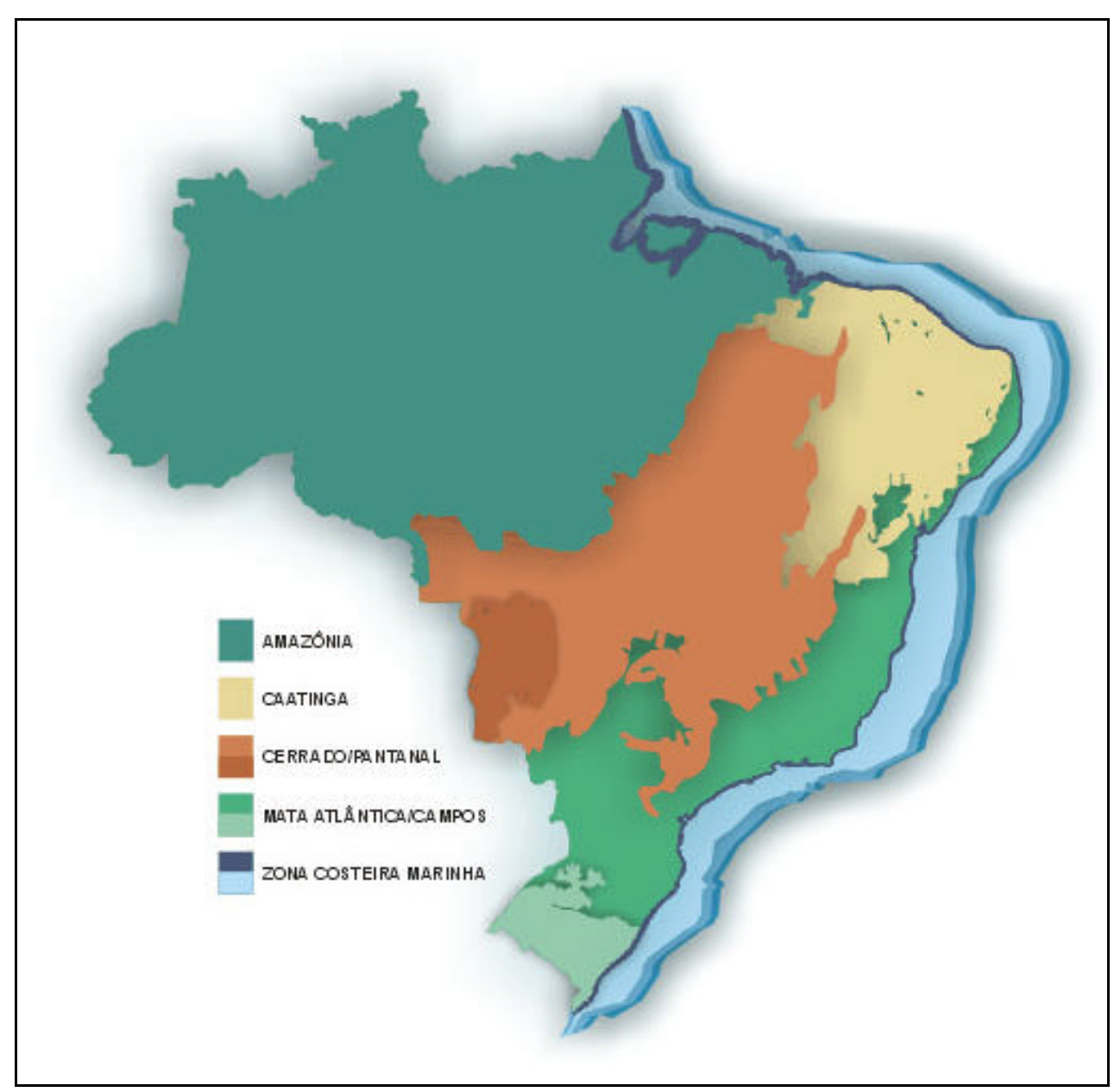

Fonte: Ministério do Meio Ambiente 


\subsection{6- Ecossistemas}

Os ecossistemas fazem parte de um bioma e são definidos formalmente como: "unidade funcional de base em ecologia, porque inclui, ao mesmo tempo, os seres vivos e o meio onde vivem, com todas as interações recíprocas entre o meio e os organismos" (DAJOZ, 1973).

Um exemplo disso é quando identificamos os diversos ecossistemas presentes na zona costeira e marinha, tais como: manguezais, restingas, costões rochosos, praias, dunas, recifes coralinos etc. (Ministério do Meio Ambiente)

Já existem países onde as atividades preservacionistas ocorrem de forma espontânea por preocuparem-se e perceberem que esta é uma necessidade vital para o desenvolvimento sustentável.

A diminuição dos índices de desmatamento no Brasil é uma prioridade do governo e da sociedade brasileira. Para alcançar esse objetivo, o Ministério do Meio Ambiente tem investido no aperfeiçoamento de políticas de prevenção, monitoramento, licenciamento e fiscalização do desmatamento e queimadas, em conjunto com incentivos para atividades econômicas sustentáveis.

Nos anos recentes, o Sensoriamento Remoto (SR) e os SIG's têm se revelado cada vez mais como ferramentas de alta potencialidade para aumentar a eficiência e eficácia das políticas de monitoramento e controle do desmatamento e queimadas.

\section{4- Pólos Ecoturísticos}

Localidades ou regiões caracterizadas pela auto-potencialidade da atividade ecoturística e razoável infra-estrutura.

No Brasil existem 96 pólos ecoturísticos em atividade que com a ajuda do Geoprocessamento poderão ser bem melhor aproveitados e monitorados, podendo auxiliar na conservação e recuperação de áreas degradadas. 
Figura 2: Mapa dos Pólos de Ecoturismo no Brasil.

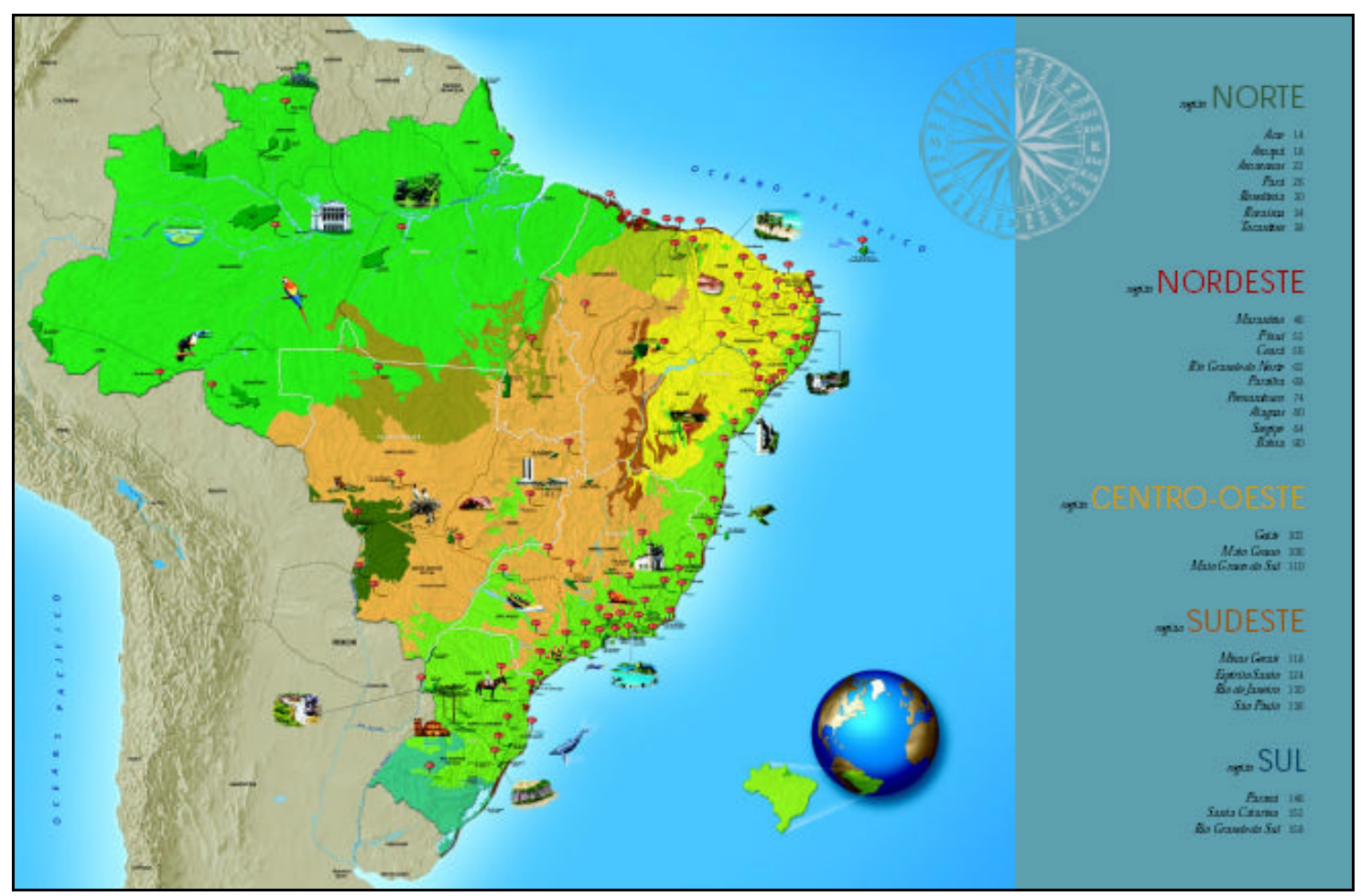

Fonte: Embratur.

\section{2- Geoprocessamento e sua Evolução}

A história do mapeamento e, por conseguinte, a do Geoprocessamento teve início em meados do século $\mathrm{XVI}$, muito embora os primeiros bons mapas começassem a ser compilados só entre o final do século XIX e início do século XX.

Esses mapas eram confeccionados com base em observações de campo que, por sua vez, tinham como base planimétrica cartas topográficas exploratórias ou de reconhecimento e, por conseguinte, apresentavam composições florísticas incompletas e com sérios problemas de deslocamento espacial.

Só a partir da primeira grande guerra, com a utilização de fotografias aéreas para fins florestais nos Estados Unidos, Canadá e Alemanha, é que começaram a ser produzidos mapas mais corretos, face à reconstrução em laboratório, das três dimensões do terreno, através de técnicas fotogramétricas.

No início da década de 40, com o advento da fotografia infravermelha 
colorida, a história do mapeamento ganhou maior dinâmica tendo em vista a possibilidade de se poder melhor estudar diferentes condições dos povoamentos.

Na década de 50, com o aparecimento das imagens de radar, outra frente se abriu, na cartografia, especialmente para estudos fitogeográficos regionais em áreas tropicais.

Os primeiros Sistemas de Informação Geográfica surgiram na década de 60, no Canadá, como parte de um programa governamental para criar um inventário de recursos naturais. Estes sistemas, no entanto, eram muito difíceis de usar, pois não existiam monitores gráficos de alta resolução, os computadores necessários eram excessivamente caros e a mão de obra tinha que ser altamente especializada. Além disto, a capacidade de armazenamento e a velocidade de processamento eram muito baixas. Ao longo dos anos 70 foram desenvolvidos novos e mais acessíveis recursos de hardware, tornando viável o desenvolvimento de sistemas comerciais. Foi então que a expressão Geographic Information System foi criada.

Os anos 70 foram basicamente consagrados ao aperfeiçoamento de sistemas imageadores multiespectrais, tanto instalados em aeronaves quanto espaçonaves. Com o lançamento do primeiro satélite da série Landsat em 1972, começaram a ser postos em prática três conceitos que hoje são da mais alta importância: "sistema multiestágio", "sistema multiespectral" e "multitemporal". O ponto chave desses conceitos é basicamente a obtenção de dados de forma rápida, detalhada e econômica, aproveitando ao máximo cada nível de levantamento, de maneira repetitiva e multiespectral.

A década de 80 representa o momento quando a tecnologia de sistemas de informação geográfica inicia um período de acelerado crescimento que dura até os dias de hoje. Até então limitados pelo alto custo do hardware e pela pouca quantidade de pesquisa específica sobre o tema, os GIS (Sistema de Informação Geográfica) se beneficiaram grandemente da massificação causada pelos avanços da microinformática e do estabelecimento de centros de estudos sobre o assunto. Nos EUA, a criação dos centros de pesquisa que formam o NCGIA - National Centre for Geographical Information and Analysis (NCGIA, 1989) marca o estabelecimento do Geoprocessamento como disciplina científica independente. 
Na década de 90, muitas atividades comuns ao planejamento ambiental são facilmente exercidas em um SIG (Sistema de Informação Geográfica), como simular a realidade do espaço geográfico, integrar informações espaciais, ou gerar mapas (Ball, 1994). Denègre (1994) ressalva que a área na qual ocorre o desenvolvimento mais rápido de aplicação ou utilização do SIG é de planejamentos urbanos, pelo fato de que no meio urbano concentram-se os conflitos. No entanto, ele aponta as aplicações ambientais como uma área em franco desenvolvimento, inclusive o Ecoturismo.

A introdução do Geoprocessamento no Brasil inicia-se a partir do esforço de divulgação e formação de pessoal feito pelo prof. Jorge Xavier da Silva (UFRJ), no início dos anos 80. A vinda ao Brasil, em 1982, do Dr. Roger Tomlinson, responsável pela criação do primeiro SIG (o Canadian Geographical Information System), incentivou o aparecimento de vários grupos interessados em desenvolver a tecnologia, entre os quais podemos citar: UFRJ: O grupo do Laboratório de Geoprocessamento do Departamento de Geografia da UFRJ, sob a orientação do professor Jorge Xavier, desenvolveu o SAGA (Sistema de Análise Geo-Ambiental). O SAGA tem seu forte na capacidade de análise geográfica e vem sendo utilizado com sucesso como veículo de estudos e pesquisas.

- MaxiDATA: os então responsáveis pelo setor de informática da empresa de aerolevantamento AeroSul criaram, em meados dos anos 80, um sistema para automatização de processos cartográficos. Posteriormente, constituíram a empresa MaxiDATA e lançaram o MaxiCAD, software largamente utilizado no Brasil, principalmente em aplicações de Mapeamento por Computador. Mais recentemente, o produto dbMapa permitiu a junção de bancos de dados relacionais a arquivos gráficos MaxiCAD, produzindo uma solução para "desktop mapping (cartografia de mesa)" para aplicações cadastrais.

- CPqD/TELEBRÁs: O Centro de Pesquisa e Desenvolvimento da TELEBRÁS iniciou, em 1990, o desenvolvimento do SAGRE (Sistema Automatizado de Gerência da Rede Externa), uma extensiva aplicação de Geoprocessamento no setor de telefonia. Construído com base num ambiente de um SIG (VISION) com um banco de dados cliente-servidor (ORACLE), o SAGRE envolve um significativo desenvolvimento e personalização de software. 
No início deste século já era comum o uso da estratégia de planejamento para obter decisões acerca de formas alternativas de melhor utilizar os recursos disponíveis, mas a discussão central estava voltada aos terrenos urbanos e às múltiplas funções de uma cidade.

No Brasil, a premissa era planejar e gerenciar através de zoneamentos ambientais, usando como unidades de planejamento as bacias hidrográficas, como apresentado na Lei $n^{0}$ 6.938, da Política Nacional de Meio Ambiente (PNMA), de 1981. Independentemente dos objetivos ou do local planejado, esta estratégia exigia a espacialização de um conjunto amplo de dados que necessitam ser comparados, sobrepostos e avaliados de maneira holística. Dessa forma, o uso dos sistemas computacionais capazes de governar bancos de dados georreferenciados passa a ser imprescindível e os SIG são cada vez mais desenvolvidos para permitir a formulação de diagnósticos, prognósticos, avaliação de alternativas de ação e manejo ambiental (Hendrix et al., 1988). Sua utilização pode reduzir substancialmente o tempo e o custo de elaboração de um plano que envolve mapeamentos, como exemplificam Lees e Ritman (1991).

$\mathrm{Na}$ atualidade, face a rapidez com que as transformações se processem, já se observa a necessidade de "mapas dinâmicos", isto é, "monitoramento", ou seja, mapeamento periódico da mesma área com a finalidade de se estudar e analisar a degradação com o intuito de prevenir e/ou recuperar.

Poucos autores tratam a ciência separadamente da tecnologia, tornando-se inevitável que muitos pesquisadores e principalmente pessoas que desconhecem a referida área façam a indissociação entre Geoprocessamento e Sistemas de Informação Geográfica (SIG). Tal fato é perfeitamente compreensível levando-se em consideração que SIG está inserido no contexto do que é conhecido como Geoprocessamento.

Segundo Rodrigues (1990), o Geoprocessamento é tido como a tecnologia de coleta e tratamento de informações espaciais e de desenvolvimento de sistemas que as utilizam, apresentando uma classificação dos Sistemas de Geoprocessamento em aplicativos, de informação e especialistas:

- sistemas aplicativos: conjuntos de programas que realizam operações 
associadas a atividades de projeto, análise, avaliação, planejamento, etc, em áreas tais como Transportes, Mineração, Hidrologia, Urbanismo; são sistemas voltados à representação de entes de expressão espacial e a realização de operações sobre estas representações; visam a realização de um largo espectro de tarefas e podem ser grupados segundo classes de sistemas voltados à entrada de dados, à saída de dados, à saída de dados e a realização de tarefas específicas; como por exemplo: projeto assistido por computador, mapeamento automatizado;

- sistemas de informações: SIG, stricto sensu, denota software que desempenha as funções de coleta, tratamento e apresentação de informações sobre entes de expressão espacial e sobre o contínuo espacial. SIG, lato sensu, denota o software; o hardware; os procedimentos de entrada e saída dos dados; fluxos de dados de supridores para o sistema e deste para os consumidores; normas de codificação de dados; normas de operação; pessoal técnico; etc, que desempenham as funções de coleta, tratamento e apresentação de informações.

- sistemas especialistas: sistemas computacionais que empregam o conhecimento na solução de problemas que normalmente demandariam a inteligência humana; emulam o desempenho de um especialista atuando em uma dada área do conhecimento.

Conforme os esclarecimentos de Rodrigues (1990), o estabelecimento destas classes não significa que sistemas de geoprocessamento tenham uma única classificação, pelo contrário, os sistemas existentes possuem, em sua grande maioria, características múltiplas com predominância de um particular conjunto de funções, e conclui afirmando que, subjacente a todos estão as técnicas e metodologias de desenvolvimento de sistemas computacionais e as de tratamento de dados espaciais. Baseado no conteúdo destas afirmações constata-se uma relativa dificuldade em diferenciar os diferentes sistemas de geoprocessamento, tornando-se relevante explicitar melhor algumas definições:

- CADD (Computer Aided Design and Drafting), ou Projeto Assistido por Computador, é uma tecnologia normalmente empregada pelo CAM (Computer Assisted Mapping), ou Mapeamento Assistido por Computador, para a produção de mapas como substituição ao processo cartográfico tradicional. Os dados são 
organizados em camadas (layers), empregados para organizar as feições do mapa por temas (themes). CAM reduz em muito o tempo de produção de mapas e possibilita economia de recursos financeiros comparando aos processos cartográficos tradicionais, tornando as atualizações mais práticas, uma vez que modifica somente o elemento selecionado. CAM, entretanto, não é um sistema muito adequado para realizar análises; as relações espaciais não são definidas na estrutura de dados, requerendo processamentos especiais para a inspeção de tais relações, o que torna demorada a resposta a perguntas complexas.

- AM/FM: Automated Mapping, ou mapeamento Automatizado, Facility Management, isto é, Gerenciamento de Serviços de Utilidade Pública, baseiam-se também em tecnologia CADD. Entretanto, a apresentação gráfica geralmente não é tão precisa e detalhada como em sistemas CAM; a ênfase de AM/FM está centrada no armazenamento, na análise e na emissão de relatórios. As relações entre os componentes do sistema de utilidade pública são definidas como redes (Networks) que são associadas à atributos, permitindo assim modelar e analisar a operação do sistema de utilidade pública. Atributos não-gráficos podem ser ligados aos dados gráficos. Dentre as limitações estão a não-definição de relações espaciais.

- GIS: Geographic Information System, ou Sistema de Informação Geográfica, é mais recomendado para a análise de dados geográficos; difere dos dois sistemas anteriormente apresentados por definir as relações espaciais entre todos os elementos dos dados. Esta convenção conhecida como topologia dos dados, vai além da mera descrição da localização e geometria das feições cartográficas. A Topologia também descreve como as feições lineares estão conectadas, como as áreas são limitadas, e quais áreas são contíguas. Para definir a topologia do mapa, o GIS usa uma estrutura de dados especial, empregando nós (nodes) arcos (lines) e áreas (polygons). O GIS também contém dados atributos, além de dados geométricos espaciais, os quais são associados com os elementos topológicos, provendo maiores informações descritivas. Por permitir acesso a ambos os dados (espaciais e atributos), ao mesmo tempo, o SIG possibilita buscar o dado atributo e relacioná-lo com o dado espacial e vice-versa.

Portanto, observa-se que enquanto CAM e AM/FM são empregados para o armazenamento, a manipulação e a recuperação de dados geográficos, um SIG 
construído especificamente para efetuar análises espaciais torna-se necessário para analisar de forma completa os dados geográficos.

\section{1 - Conceitos Básicos de Geoprocessamento}

Um Sistema de Informações Geográficas (GIS) é um sistema de manejo de base de dados computadorizados projetado para coleta, armazenagem, análise e visualização de dados espaciais. Pacotes de software que podem ser usados para a cartografia incluem sistemas para desenho e projeto auxiliado por computador (CAD), sistemas cartográficos auxiliados por computador, sistemas para o manejo de facilidades e cartografia automática (AM/FM), ou sistemas de informação sobre o terreno (LIS). Consideraremos todos estes como Sistema de Informação Geográfica.

Geoprocessamento é uma tecnologia transdisciplinar, que, através da axiomática da localização e do processamento de dados geográficos, integra várias disciplinas, equipamentos, programas, processos, entidades, dados, metodologias e pessoas para coleta, tratamento, análise e apresentação de informações associadas a mapas digitais georreferenciados (ROCHA, 2000).

Inúmeros autores dissertam sobre Ecoturismo e Geoprocessamento, porém, em relação ao ecoturismo com base nas informações dos próprios autores, muito ainda deve ser discutido e revisado. Quanto ao geoprocessamento, os conceitos não diferem muito uns dos outros, facilitando assim a compreensão do assunto tratado neste trabalho e como pode auxiliar o Ecoturismo.

O Geoprocessamento que denota a disciplina do conhecimento que utiliza técnicas matemáticas e computacionais para o tratamento da informação geográfica, vem influenciando de maneira crescente as áreas de Cartografia, Análise de Recursos Naturais e outras. Torna ainda possível automatizar a produção de documentos cartográficos de relevante importância para o Ecoturismo. 


\section{3- Conceitos Básicos de Cartografia}

O conceito de Cartografia tem suas origens intimamente ligadas às inquietações que sempre se manifestaram no ser humano, no tocante a conhecer o mundo que ele habita.

O vocábulo CARTOGRAFIA, etmologicamente - descrição de cartas, foi introduzido em 1839, pelo segundo Visconde de Santarém - Manoel Francisco de Barros e Souza de Mesquita de Macedo Leitão, (1791/1856). A despeito de seu significado etmológico, a sua concepção inicial continha a idéia do traçado de mapas. No primeiro estágio da evolução o vocábulo passou a significar a arte do traçado de mapas, para em seguida, conter a ciência, a técnica e a arte de representar a superfície terrestre.

"CARTOGRAFIA - no sentido lato da palavra não é apenas uma das ferramentas básicas do desenvolvimento econômico, mas é a primeira ferramenta a ser usada antes que outras ferramentas possam ser postas em trabalho." ${ }^{1}$

O conceito da Cartografia usado na atualidade é "A Cartografia apresenta-se como o conjunto de estudos e operações científicas, técnicas e artísticas que, tendo por base os resultados de observações diretas ou da análise de documentação, se voltam para a elaboração de mapas, cartas e outras formas de expressão ou representação de objetos, elementos, fenômenos e ambientes físicos e socioeconômicos, bem como a sua utilização."

O processo cartográfico, partindo da coleta de dados, envolve estudo, análise, composição e representação de observações, de fatos, fenômenos e dados pertinentes a diversos campos científicos associados a superfície terrestre.

O planejamento de qualquer atividade que de alguma forma se relaciona com o espaço físico que habitamos requer, inicialmente, o conhecimento deste espaço. Neste contexto, passa a ser necessária alguma forma de visualização da região da superfície física do planeta, onde desejamos desenvolver nossa atividade. Pode-se distinguir, no processo cartográfico, três fases distintas: a concepção, a produção e a interpretação ou utilização. As três fases admitem uma só origem, os levantamentos

\footnotetext{
${ }^{1}$ ONU, Departament of Social Affair. Modern Cartography - Base Maps For Worlds Needs. Lake Success.
} 
dos dados necessários à descrição de uma realidade a ser comunicada através da representação cartográfica.

A carência de mapeamento no Brasil, principalmente em escalas grandes, é agravada pelo fato de grande parte encontrar-se desatualizado, fazendo com que a sua utilização não alcance os objetivos para os quais foram elaborados.

Os métodos para produção de mapas, assim como para atualização cartográfica evoluíram gradativamente com 0 advento de novos processos tecnológicos, principalmente na área da informática com o mapeamento digital, a utilização de Sistemas de Posicionamento Global (GPS), tratamento digital de imagens e Sistemas de Informação Geográfica (SIG's).

É indiscutível a importância do sensoriamento remoto para a cartografia. A agilidade e a redução de custos obtidos através da utilização de imagens orbitais para atualização cartográfica vem acompanhadas de uma qualidade cada vez maior no que diz respeito à resolução espacial e multiespectral de alta tecnologia, atendendo aos requisitos de precisão planimétricas exigidos para as escalas do mapeamento sistemático. Deve-se ressaltar o menor custo aquisição de imagens se comparado a realização de novo recobrimento aéreo.

Os Sistemas de Informações Geográficas são ferramentas poderosas, empregadas na integração e análise de dados provenientes de fontes muito díspares, como imagens fornecidas por satélites terrestres, mapas (de solos, de propriedade da Terra, topográficos, de vegetação), cartas, climatológicas, censos etc. Podem ser caracterizados como Sistemas constituídos a partir da escolha, obtenção e armazenagem de dados, de modo a fornecer ao usuário meios para a sua recuperação e manipulação com o uso de computadores. Tais dados estão, geralmente, vinculados a uma dada região geográfica, condição que os diferencia dos Sistemas puramente de gerenciamento de bases de dados. Tecnicamente, dizse que os dados estão georreferenciados ou geocodificados.

Os mapas sofrem contínua desatualização pela dinâmica ação do homem no ambiente. As mudanças no meio levam diretamente à necessidade de atualização cartográfíca, que garantirá a utilidade do mapeamento. Por isso, a atualização precisa ser permanente, já que servirá para a manutenção da base cartográfica. 
Numa atualização, o mais importante é a detecção de mudanças, que pode vir de três fontes:

- órgãos públicos que lidam diariamente com feições do meio físico e acompanham suas alterações como as companhias de energia elétrica, saneamento básico, telefonia, setores das prefeituras responsáveis pela aprovação de novos loteamentos e construções;

- comparação de um novo conjunto de fotografias aéreas ou imagens de satélites com mapas antigos;

- constatação direta no terreno, comparando o mapa existente com a situação física real. Também comenta que a sistemática adotada dependerá, principalmente, da escala da carta, conseqüência direta de sua finalidade, além do tipo e método de atualização. Quanto ao tipo, a atualização pode ser rápida, parcial ou completa. (CARNEIRO, 1980)

\section{1- SISTEMA DE PROJEÇÕES CARTOGRÁFICAS}

\subsection{1- Projeções Cartográficas}

Conforme se pode verificar, a história dos mapas reflete a preocupação que o homem sempre teve em representar a superfície terrestre, utilizando técnicas de acordo com o estágio de seus conhecimentos. Com o passar do tempo, impõe-se a preocupação em obter resultados cartográficos com o maior rigor científico possível, tendo-se duas formas principais de representar a superfície terrestre: globos e mapas.

Os globos geográficos constituem-se no modo mais fiel de representar a Terra, mesmo sabendo-se que nosso planeta não é uma esfera perfeita. Entretanto, a diferença entre os eixos polar e equatorial é tão pequena que seria praticamente impossível representá-la em escala tão reduzida nos globos de mesa. Por isso, podemos ter certeza que tais globos são os modelos mais parecidos com a superfície real da Terra. Mas os globos possuem algumas vantagens e desvantagens que fazem com que a cartografia dê preferência para os mapas, os 
quais, por sua vez, também não são perfeitos. Por isso, faz-se necessário tecer algumas considerações sobre certas vantagens e desvantagens de globos e mapas.

Os globos não permitem que o observador tenha visão de toda a superfície terrestre ao mesmo tempo, ou seja, em razão de sua esfericidade eles nos mostram sempre em de seus lados e escondem o outro. Isto já não ocorre com os mapas, pois estes podem representar o mundo inteiro ao mesmo tempo (planisférios);

Podemos girar os globos para termos uma visão centrada em qualquer ponto da superfície terrestre, o que já não se pode fazer com os mapas, pois estes são fixos;

O manuseio dos globos é muito incômodo, como por exemplo: tirar cópias, obter medidas com instrumentos, transportar. Os mapas, por sua vez, possuem grande facilidade de manuseio;

Os globos, para que fiquem num tamanho razoável e permitam mais fácil manuseio, precisam representar a Terra num escala muito pequena, o que leva a muitas generalizações e também poucas informações. Os mapas, porém, podem representar a Terra em várias escalas, permitindo que se possa planejar a quantidade de informações, bem como seu nível de precisão;

A confecção dos globos requer grande dispêndio de materiais e equipamentos especiais, o que encarece bastante seu custo ao consumidor. Com relação aos mapas, estes têm um custo bem mais acessível;

De modo geral, os globos são a representação mais fiel da Terra no que diz respeito à forma do planeta, forma e dimensões dos acidentes geográficos, além da distribuição das terras e águas. Os mapas, no entanto, ao reproduzirem numa superfície plana (o papel) aquilo que na realidade é curvo (a superfície terrestre), sempre apresentam distorções. Não existe o mapa perfeito. Mesmo assim, dá-se preferência pelo seu uso em lugar dos globos, tendo em vista uma série de vantagens que eles apresentam, conforme vimos anteriormente. Por isso é que se faz necessário um estudo das projeções cartográficas, para que se possa entender sua relação com os mapas e o importante papel que elas representam na Cartografia. 


\subsection{2- Classificação das Projeções}

Os engenheiros americanos, Charles H. Deetz e Oscar S. Adams, do Coast and Geodetic Survey, em seu livro Elements of Map Projection, explicam que "não existe uma forma pela qual as projeções possam ser divididas em classes que sejam reciprocamente excludentes, isto é, em que nenhuma projeção pertença a uma classe, e somente a uma".

Os mesmo autores, contudo, oferecem a seguinte classificação:
a) equivalentes;
b) conformes;
c) azimutais;
d) perspectivas ou geométricas;
e) convencionais.

Já o Almirante Múcio Piragibe Ribeiro de Bakker, em seu manual, Cartografia - Noções Básicas, publicado pela Diretoria de Hidrografia e Navegação, as divide segundo este esquema:

1. Quanto ao método:
a) geométricas
b) perspectivas
c) pseudoperspectivas
d) analíticas
e) simples ou regulares
f) modificadas ou irregulares
g) convencionais 
2. Quanto à situação do ponto de vista:
a) gnomônica
b) estereográfica
c) ortográfica

3. Quanto à superfície de projeção:
a) planas ou azimutais
b) por desenvolvimento
c) cônicas e policônicas
d) cilíndricas
e) poliédricas
f) planas ou azimutais
g) polares
h) equatoriais ou meridionais
i) horizontais ou oblíquas

4. Quanto à situação da superfície de projeção:
a) cônicas ou policônica
b) normais
c) transversas
d) horizontais ou oblíquas
e) cilíndricas
f) equatoriais
g) transversas ou meridianas
h) horizontais ou oblíquas 
5. Quanto às propriedades:
a) eqüidistantes
b) meridianas
c) transversais
d) azimutais ou ortodrômicas
e) equivalentes
f) conformes
g) afilática

O esquema é cuidadoso e tem a vantagem de ser panorâmico e sem ambigüidade. Elimina possíveis dúvidas a respeito de qualquer tipo de projeção;

De acordo com o nosso propósito de não nos afastarmos da didáticas, é preferível adotar a seguinte classificação, a qual se restringe a representar as propriedades das projeções:
a) equivalentes;
b) conformes;
c) eqüidistantes;
d) azimutais ou zenitais;
e) afiláticas ou arbitrárias. (DUARTE, 1991)

4- Geoprocessamento como Apoio à Decisão

Para alcançar o objetivo proposto, utilizourse o geoprocessamento como ferramenta principal para análise dos dados ambientais, e que engloba diversas técnicas como Sensoriamento Remoto, foto interpretação, digitalização de mapas, GPS e SIG. 
Geoprocessamento pode ser definido como um ramo do processamento de dados que opera transformações nos valores contido em uma base de dados referenciada territorialmente (geocodificada), usando recursos analíticos, geográficos e lógicos para obtenção e apresentação das informações desejadas (XAVIER, 1992).

Dados ambientais e variáveis ambientais, são conjuntos de valores relacionados aos ambientes. Quando os dados ambientais recebem um significado atributo pelo ser humano, transformam-se em informações ambientais (TEIXEIRA, 1992).

Os dados ambientais possuem o atributo de localização, o que permite a criação de bases geocodificadas relacionadas a estes dados. Assim, possível a analise destes dados ligados a outras propriedades com extensão e vizinhança ou ainda serem observados atributos temporais através de análises retrospectivas, avaliações e simulações de situações futuras (prospecções), pois os dados ambientais não são estáticos (XAVIER, 1992).

Além de serem localizáveis, o que é imprescindível para o geoprocessamento, os dados ambientais possuem as características de serem diversificados e numerosos. Exigem, portanto, capacidade de armazenamento conferida pela memória computadorizada e o auxilio para interpretação dos dados conferido pelos SIG's. Estes utilizam-se de uma base de dados computadorizada que contém informação espacial, sobre a qual atua uma série de programas e processos de análise (que são seus constituintes básicos), cuja característica principal é focalizar o relacionamento de determinado fenômeno da realidade (ou dado ambiental) com sua localização espacial.

Baseia-se uma tecnologia de armazenamento, análise e tratamento de dados espaciais, não espaciais e temporais e na geração de informações correlatas (TEIXEIRA, 1992).

Dentre as técnicas englobadas no geoprocessamento, o SIG tem se tornado imprescindível para os estudos ambientais devido a uma série de fatores, como expõe Lorini (2002): 
- "Incorporam a dimensão espacial dos fenômenos em estudo de forma consistente e definitiva;

- Trabalham a natureza complexa e multidisciplinar das variáveis facilitando a analise integradora;

- Otimizam o tempo e forma de obtenção de informações analíticas e sintéticas tornando mais robusto o apoio às decisões;

- Geram informações simultaneamente precisas e de fácil compreensão melhorando a cooperação institucional e privada."

O geoprocessamento vem mostrando eficiente ferramenta para 0 planejamento, tomada de decisões e aumento da eficiência das ações de cunho. Mas vale ressalvar a necessidade de cautela e planejamento em seu uso, tomando cuidado para desenvolver procedimentos de analises que explicitem o modo de pensar do pesquisador. Para tanto, este deve determinar o que guardar em termos de dados ambientais, e o que fazer com eles através da definição de objetivos (SAITO, 1995).

\section{5- Planejamento Ambiental}

Os planejamentos ambientais são elaborados como sistemas estruturados que envolvem etapas distintas, conforme ilustra o Quadro 1. Cada etapa compreende uma série de procedimentos que são desenvolvidos usando-se metodologias cujos arcabouços originaram-se dos planejamentos urbanos, sistemas de avaliação de recursos hídricos e avaliações de impacto ambiental.

Uma das questões mais importantes a ser considerada em planejamentos ambientais é que o processo de tomada de decisão está basicamente fundamentado na coleta e análise de informações sobre o ambiente em estudo, cujos dados envolvidos normalmente mostram alta complexidade.

Grande parte dos planejamentos ambientais organiza o banco de dados baseada nas informações temáticas (como solo, recursos hídricos, uso da terra) é 
necessário selecionar a escala de trabalho em função da área de estudo e dos objetivos propostos. Então, o banco de dados e o próprio SIG devem estar ajustados à escala determinada pois, se alterada, a qualidade ou dimensão dos "problemas ambientais" mudam. Assim, problemas locais, como em nível municipal, referem-se em grande parte a questões pontuais, que abrangem pequenas faixas de terreno ou ecossistemas. Tratando-se de um planejamento regional, como por exemplo, uma bacia hidrográfica que engloba vários municípios, os planejamentos ambientais, de forma geral, centralizam seus estudos no entendimento da dinâmica regional bem como dos problemas ambientais que interagem entre municípios.

Quadro 1. Etapas e procedimentos metodológicos em planejamento ambiental.

\begin{tabular}{|c|c|c|}
\hline ETAPAS & PROCEDIMENTOS & EXEMPLOS DE MÉTODOS E TÉCNICAS \\
\hline \multirow[t]{2}{*}{ DEFINIÇÃO DE OBJETIVOS } & $\begin{array}{c}\text { OBTENÇÃO DE CONCEITOS ENTRE } \\
\text { VERTENTES }\end{array}$ & \multirow{2}{*}{$\begin{array}{l}\text { - Métodos de } \\
\text { questionamento direto } \\
\text { (entrevistas) } \\
\text { - Métodos de } \\
\text { questionamento indireto } \\
\text { (Delphi) }\end{array}$} \\
\hline & $\begin{array}{l}\text { - Institucional } \\
\text { - Técnico-científica } \\
\text { - Comunitária } \\
\end{array}$ & \\
\hline \multirow{2}{*}{$\begin{array}{l}\text { Delimitação da área de } \\
\text { estudo }\end{array}$} & ÁREA DE INFLUÊNCIA & \\
\hline & $\begin{array}{l}\text { - Area Institucional / Bacia Hidrográfica } \\
\text { - Global / Regional / Local }\end{array}$ & \\
\hline \multirow{2}{*}{$\begin{array}{l}\text { Definição de categorias, } \\
\text { fatores e parãmetros } \\
\text { indicadores }\end{array}$} & BANCO DE DADOS & \multirow[b]{2}{*}{$\begin{array}{l}\text { - Listagens } \\
\text { (simples/descritivas/ponderadas) } \\
\text { - Diagramas e Redes de Interação } \\
\text { - Árvores de Decisão } \\
\text { - Índices de Frequência } \\
\text { - Holmes } \\
\text { - EES } \\
\text { - Precedências }\end{array}$} \\
\hline & $\begin{array}{l}\text { - Levantamento de dados (secundarıos, } \\
\text { observações diretas) } \\
\text { - Avaliação do "pool" de informações, seleção e } \\
\text { parãmetros e dimensionamento dos dados } \\
\text { (qualitativos/quantitativo; multicategórico/binário; } \\
\text { contínuo/discreto; nominal/ordinal/cardinal) } \\
\text { - Ponderação das categorias; fatores e parãmetros } \\
\text { indicativos }\end{array}$ & \\
\hline \multirow{2}{*}{$\begin{array}{l}\text { Seleção da(s) escala(s) } \\
\text { de trabalho }\end{array}$} & GERAL / DETALHE & \\
\hline & - Avaliações Sintéticas/Analíticas & \\
\hline \multirow[b]{2}{*}{ DIAGNÓSTICO } & ANÁLISE INTEGRADA & \multirow{2}{*}{$\begin{array}{l}\text { - Inventário } \\
\text { - Métodos Espaciais }\end{array}$} \\
\hline & $\begin{array}{l}\text { - Identificação do quadro de fragilidade e } \\
\text { potencialidades do meio, acertos e conflitos }\end{array}$ & \\
\hline \multirow{2}{*}{$\begin{array}{l}\text { PROGNÓSTICO E } \\
\text { IDENTIFICACCÃO DE } \\
\text { ALTERNATIVAS }\end{array}$} & AVALIAÇÕES TEMPORAIS & \multirow[b]{2}{*}{$\begin{array}{l}\text { - Modelagem } \\
\text { - Simulação } \\
\text { - Clustering descriminantes } \\
\text { - Análise de interdependência }\end{array}$} \\
\hline & $\begin{array}{l}\text { - Qualificação do meio e classificação das } \\
\text { informações } \\
\text { - Identificação de cenários e soluções alternativas } \\
\text { (curto, médio e longo prazo) }\end{array}$ & \\
\hline \multirow[t]{2}{*}{ TOMADA DE DECISÃO } & ORDENAÇÃO TERRITORIAL & \multirow{3}{*}{$\begin{array}{l}\text { - Métodos de ordenação } \\
\text { - Matrizes Cruzadas } \\
\text { - Métodos Multicriteriais } \\
\text { - Modelagem } \\
\text { - Técnicas ACB } \\
\end{array}$} \\
\hline & $\begin{array}{l}\text { - Modelo de organização territorial } \\
\text { - Avaliacóes jurídicas, administrativas e financeiras } \\
\text { das alternativas para ordenação } \\
\text { - Hierarquização de alternativas } \\
\text { - Definição do modelo de organização territorial }\end{array}$ & \\
\hline \multirow{2}{*}{$\begin{array}{c}\text { FORMULAÇÃO DE } \\
\text { DIRETRIZES, METAS E } \\
\text { POLÍTICAS }\end{array}$} & $\begin{array}{l}\text { INSTRUMENTAÇÃO TÉCNICA, JURÍDICA E } \\
\text { ADMINISTRATIVA }\end{array}$ & \\
\hline & $\begin{array}{l}\text { - Definição de normas técnicas para organização } \\
\text { territorial } \\
\text { - Elaboração de planos e programas de manejo e } \\
\text { recuperação ambiental } \\
\text { - Propostas de monitoramento e vigilância } \\
\text { - Proposicão de organogramas institucionais e } \\
\text { administrativos } \\
\text { - Elaboração de mecanismos de gestão }\end{array}$ & $\begin{array}{l}\text { - Árvores de Decisão } \\
\text { - Sistemas Especialistas }\end{array}$ \\
\hline
\end{tabular}

Fonte: Caderno de Informações Georreferenciadas - CIG da FEC/UNICAMP. 
Em planejamento ambiental, uma grande importância atribuída aos SIG é a capacidade de construir e manter grandes bases de dados espaciais (Câmara e Freitas, 1995). Além disso, estes sistemas devem reconhecer as diferentes informações, integrar os dados e promover a projeção temporal e espacial dos dados acumuladas. Dessa forma, de acordo com Baker e Panciera (1990), a seleção do SIG deve considerar, pelo menos, o formato raster e/ou vetor, o conjunto de variáveis para incluir no modelo, o tamanho do pixel (resolução da célula) em modelos raster ou resolução (escala de mapeamento) em modelos vetor e a seleção dos modelos (algoritmo).

O modelo vetor representa fenômenos espaciais usando uma geometria de espaços contínuos para pontos posicionados (como sítios de espécies vegetais raras), linhas (como uma trilha) e áreas ou polígonos (como parcelas de terra, bacias de drenagem). É muito usado em planejamentos que situam áreas urbanas e necessitam espacializar, por exemplo, planos de transporte ou distribuição de taxação de impostos.

Em planejamentos ambientais são essenciais a representação espacial dos dados, a integração e derivação das informações existentes de uma área de estudo e a disponibilidade de SIG.

Uma das principais vantagens do SIG para planejamentos é poder apresentar os dados em diferentes níveis de detalhe, dentro de enfoques holístico ou analítico com que se estuda a região. Nestes casos, os dados (ou modelo de informação) têm que ser organizados em níveis (ou layers) de apresentação e de maneira que não necessariamente se passe de um nível a outro numa seqüência obrigatória. Esta estratégia possibilita a obtenção de uma infinidade de combinações de dados e comparações entre diferentes alternativas de ação.

\section{6- Características de um SIG}

O termo sistema de informações geográficas é aplicado para sistemas que realizam o tratamento computacional de dados geográficos. Devido a sua ampla gama de aplicações, que inclui temas como agricultura, floresta, cartografia, 
cadastro urbano e redes de concessionárias (água, energia e telefonia), há pelo menos três grandes maneiras de utilizar um SIG:

- como ferramenta para produção de mapas;

- como suporte para análise espacial de fenômenos;

- como um banco de dados geográficos, com funções de armazenamento e recuperação de informação espacial.

Estas três visões do SIG são antes convergentes que conflitantes e refletem a importância relativa do tratamento da informação geográfica dentro de uma instituição. Para esclarecer ainda mais o assunto, apresentamos a seguir algumas definições de SIG:

- Para Aronoff, Um conjunto manual ou computacional de procedimentos utilizados para armazenar e manipular dados georreferenciados;

- Segundo Burrough, Conjunto poderoso de ferramentas para coletar, armazenar, recuperar, transformar e visualizar dados sobre o mundo real;

- Conforme Cowen, um sistema de suporte à decisão que integra dados referenciados espacialmente num ambiente de respostas a problemas;

- Smith diz que um banco de dados indexados espacialmente, sobre o qual opera um conjunto de procedimentos para responder a consultas sobre entidades espaciais.

A maioria dos conceitos utilizados atualmente sobre elaboração e visualização de mapas, por computador, tem origem nos antigos mapas confeccionados manualmente por cartógrafos que,há seculos, vêm refinando a arte de representar e simbolizar uma grande variedade de características do terreno com alto nível de qualidade. Quando técnicas de computação são utilizadas para a confecção de produtos cartográficos, o caso ideal é obter do computador mapas com a mesma qualidade daqueles confeccionados manualmente.

A computação gráfica, ou visualização por computador, como hoje a entendermos, conheceu seu maior desenvolvimento a partir de 1987, por meio de 
conferências co-patrocinadas pelo Institute of Electrical and Eletronics Engineers (IEEE) e Special Interest Group on Computer Graphics (SIGGRAPH) (McCORMICK,1987).

Estas definições de SIG refletem, cada uma à sua maneira, a multiplicidade de usos e visões possíveis desta tecnologia e apontam para uma perspectiva interdisciplinar de sua utilização. A partir destes conceitos, é possível indicar as principais características em que o SPRING está incluído:

- Integrar, numa única base de dados, informações espaciais provenientes de dados cartográficos, dados de censo e cadastro urbano e rural, imagens de satélite, redes e modelos numéricos de terreno.

- Oferecer mecanismos para combinar as várias informações, através de algoritmos de manipulação e análise e para consultar, recuperar, visualizar e plotar o conteúdo da base de dados geocodificados. (INPE, 2003)

\section{7- SPRING}

O SPRING é também um SIG, entretanto será aqui tratado como um Banco de Dados Geográfico, uma vez que foi concebido com todos ferramentais de um sistema de informação dentro de estrutura de banco de dados relacionais.

Podendo ser um sistema computacional projetado para fazer mapas, embora ele possa criar mapas em diferentes escalas, em diferentes projeções e com diferentes cores, ele é capaz de identificar e informar sua localização ou distribuição, ou ainda a distribuição espacial de seus atributos. Assim, este conjunto de tecnologias se aplica, principalmente a:

- Planejamento urbano, regional, agrícola, e de transporte;

- Análise espacial ambiental, geológica, urbana, regional e de transporte;

- Gerenciamento de variados processos de distribuição, alocação e agrícolas; principalmente, uma ferramenta de análise que auxilia na tomada de decisões. 


\section{8- Tecnologias Relacionadas}

O geoprocessamento pode ser considerado como uma ciência multidisciplinar que possui contribuições de muitas áreas. De uma forma geral, as tecnologias que mais contribuem são:

- Cartografia: contribui com técnicas de confecção de mapas;

- CAD (Computer Aided Drafting) e Computação Gráfica: contribui com software, hardware, técnicas para entrada de dados, exibição, visualização representação em 2D e 3D, manipulação e representação de objetos gráficos, etc;

- Sistema de Gerenciamento de Banco de Dados (SGBD ou DBMS): constituem modelos de dados, estrutura de dados, segurança e processos de manipulação de grandes volumes de dados;

- Sensoriamento Remoto: possui técnicas de aquisição e processamento de imagens, com facilidades para obtenção de dados sobre qualquer lugar do globo terrestre, seja através de sensores orbitais (satélites) ou sensores fotográficos (aerotransportados);

- Inteligência Artificial: tecnologia que usa o computador para emular a inteligência humana. O computador atua como um especialista nas funções de desenho, mapeamento, classificações, generalização de características de mapas, etc. Assim a inteligência artificial provê modelos e técnicas de sistemas de desenho e análise;

- Estatística: provê modelos e métodos de análise dos dados, sejam gráficos ou não gráficos. As técnicas de estatística são utilizadas para verificação da qualidade durante o preprocessamento, para resumir um arquivo como um relatório de gerência dos dados, para criar dados derivados durante análises, etc;

- Informática: além de cobrir alguns dos itens já citados, a ciência da informática ainda contribui com técnicas de desenvolvimento de sistemas, evolução da tecnologia de hardware para suportar grandes cargas de processamentos de dados e a tecnologia de redes de computadores que permite a troca de informações entre equipamentos. 


\section{9- Estrutura Geral de um SIG}

A partir de uma estrutura, um Sig é capaz de associar a representação gráfica desses geo-objetos com a informação descritiva contida em seu banco de dados e também de computar novas informaçõe e exibílas sob a forma de mapas. Assim, para obter informações sobre estradas como, pavimentação, largura, comprimento ou número de vias, pode-se consultar o dado tabular(atributos) œrrespondente e apresentar os resultados de forma inteligível.

O aspecto mais fundamental tratado em um SIG é a natureza dual da informação: um dado espacial ou geográfico possui uma localização expressa como coordenadas de um mapa e atributos descritivos representados num banco convencional (Câmara Neto, 1995).

Numa visão abrangente, pode-se indicar que um SIG tem os seguintes componentes:

- Interface com usuário;

- Entrada e integração de dados;

- Funções de processamento gráfico e de imagens;

- Visualização e plotagem;

- Armazenamento e recuperação de dados (organizados sob a forma de um banco de dados geográficos).

Estes componentes se relacionam de forma hierárquica. No nível mais próximo ao usuário, a interface homem-máquina define como o sistema é operado e controlado. No nível intermediário, um SIG deve ter mecanismos de processamento de dados espaciais (entrada, edição, análise, visualização e saída). No nível mais interno do sistema, um sistema de gerência de bancos de dados geográficos oferece armazenamento e recuperação dos dados espaciais e seus atributos.

De uma forma geral, as funções de processamento de um SIG operam sobre dados em uma área de trabalho em memória principal. A ligação entre os dados geográficos e as funções de processamento do SIG é feita por mecanismos de 
seleção e consulta que definem restrições sobre o conjunto de dados. Exemplos ilustrativos de modos de seleção de dados são:

A figura a seguir indica o relacionamento dos principais componentes. Cada sistema, em função de seus objetivos e necessidades, implementa estes componentes de forma distinta, mas todos os subsistemas citados estão presentes num SIG.

Figura 3: Arquitetura de Sistemas de Informação Geográfica.

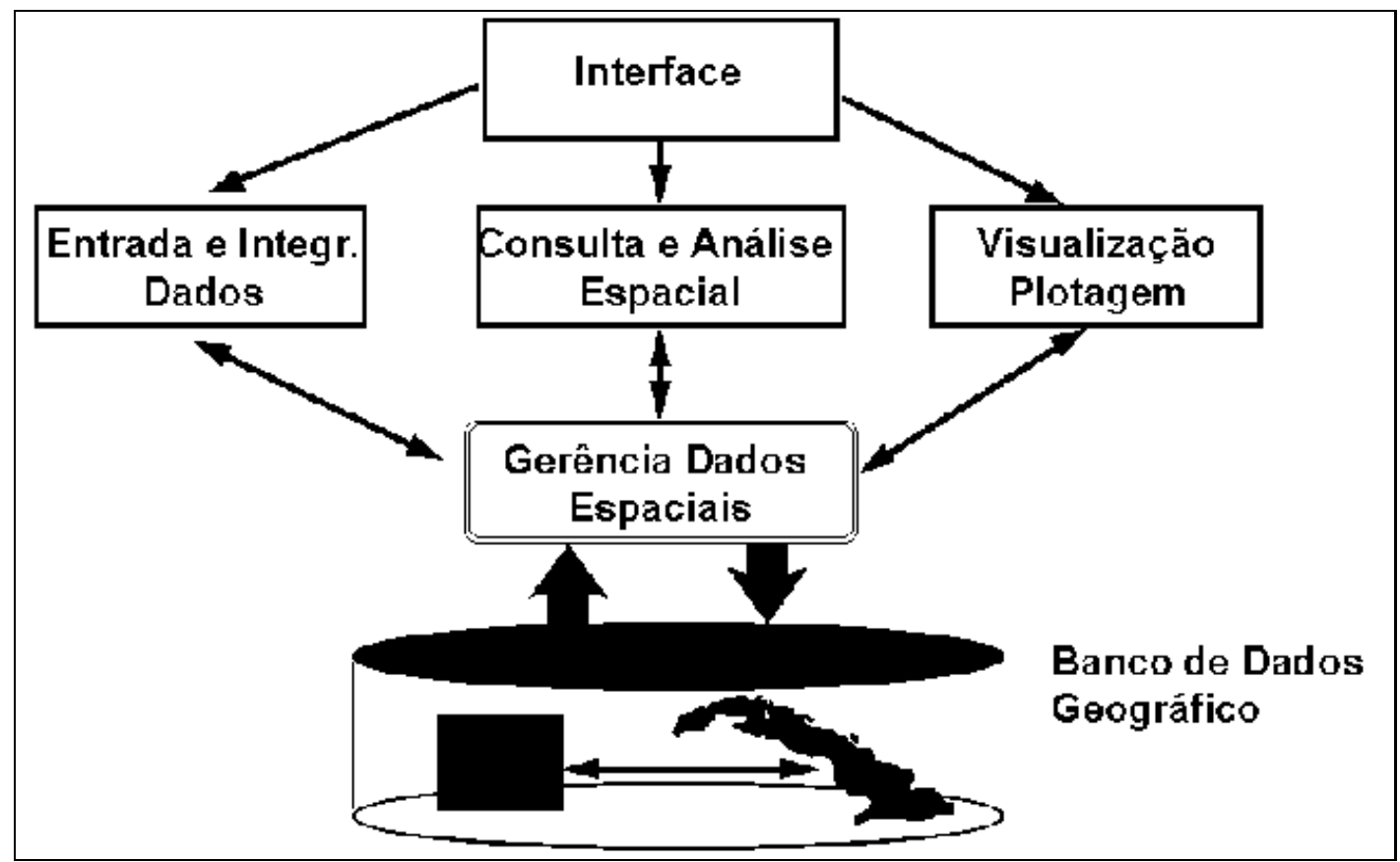

Fonte: INPE.

10 - Tipos de dados em Geoprocessamento

Um sistema de Geoprocessamento armazena a geometria e os atributos dos dados, que estão georreferenciados, isto é, localizados na superfície terrestre numa projeção cartográfica. Os dados tratados em geoprocessamento tem como principal característica a diversidade de fontes geradoras e de formatos apresentados.

À diferença de sistemas de Projeto Auxiliado por Computador (CAD), uma característica básica e geral num SIG é sua capacidade de tratar as relações espaciais entre os objetos geográficos. Denota-se por topologia a estrutura de relacionamentos espaciais (vizinhança, proximidade, pertinência) que podem se estabelecer entre objetos geográficos. 
O requisito de armazenar a geometria dos objetos geográficos e de seus atributos representa uma dualidade básica para SIG's. Para cada objeto geográfico, o SIG necessita armazenar seus atributos e as várias representações gráficas associadas.

\section{1- Evolução da Tecnologia de Geoprocessamento}

Este item traça uma visão retrospectiva e prospectiva sobre a tecnologia de Geoprocessamento, onde consideramos a existência de três gerações de SIG's.

A primeira geração (“CAD cartográfico") caracteriza-se por sistemas herdeiros da tradição de Cartografia, com suporte de bancos de dados limitado e cujo paradigma típico de trabalho é o mapa (chamado de "cobertura" ou de "plano de informação"). Desenvolvidos a partir da início da década de 80 para ambientes da classe VAX e - a partir de 1985 - para sistemas PC/DOS, esta classe de sistemas é utilizada principalmente em projetos isolados, sem a preocupação de gerar arquivos digitais de dados. Esta geração também pode ser caracterizada como sistemas orientados a projeto ("project-oriented GIS").

A segunda geração de SIG's ("banco de dados geográfico") chegou ao mercado no início da década de 90 e caracteriza-se por ser concebida para uso em ambientes cliente-servidor, acoplado a gerenciadores de bancos de dados relacionais e com pacotes adicionais para processamento de imagens. Desenvolvida em ambientes multiplataforma (UNIX, OS/2, Windows) com interfaces baseadas em janelas, esta geração também pode ser vista como sistemas para suporte à instituições ("enterprise-oriented GIS").

Pode-se prever, para o final da década de 90, o aparecimento de uma terceira geração de SIG's ("bibliotecas geográficas digitais" ou "centros de dados geográficos"), caracterizada pelo gerenciamento de grandes bases de dados geográficos, com acesso através de redes locais e remotas, com interface via WWW (World Wide Web).

Para esta terceira geração, o crescimento dos bancos de dados espaciais e a necessidade de seu compartilhamento com outras instituições requer o recurso a 
tecnologias como bancos de dados distribuídos e federativos. Estes sistemas deverão seguir os requisitos de interoperabilidade, de maneira a permitir o acesso de informações espaciais por SIG's distintos.

A terceira geração de SIG pode ainda ser vista como o desenvolvimento de sistemas orientados para troca de informações entre uma instituição e os demais componentes da sociedade ("society-oriented GIS").

A figura a seguir ilustra a evolução da tecnologia de Geoprocessamento.

Figura 4: Evolução da tecnologia de SIG.

\begin{tabular}{|c|c|c|c|}
\hline Tecnologia & CAD, Cartografia & BDados, Imagens & Sist. Distribuídos \\
\hline Uso princ. & Desenho de Mapas & Análise Espacial & Centro Dados \\
\hline Ambiente & Projetos isolados & Cliente-servidor & Multi-servid., WMW \\
\hline \multirow[t]{2}{*}{ Sistemas } & Pacotes separados & Software integrado & Interoperabilidade \\
\hline & $\begin{array}{l}\text { 1a. geração } \\
\text { (1983-1990) }\end{array}$ & $\begin{array}{l}\text { 2a. geração } \\
(1990-1997)\end{array}$ & $\begin{array}{l}\text { 3a. geração } \\
\text { (1997-?) }\end{array}$ \\
\hline
\end{tabular}

Fonte: INPE

Com base no panorama de evolução da tecnologia de Geoprocessamento apresentado acima, pretende-se atuar em duas perspectivas:

- estabelecer sólidas bases conceituais para o desenvolvimento e o aprimoramento de um SIG de segunda geração (SPRING);

- lançar idéias para o projeto e desenvolvimento da tecnologia de centros de dados geográficos, que virá para complementar as capacidades do SPRING.

O objetivo do SPRING 2.0 é ser um SIG que satisfaça a todos às necessidades de um sistema de segunda geração, isto é, um "Bancos de Dados Geográficos", pois acreditamos que a existência de um banco de dados geográfico completo é fundamental para que possamos construir bibliotecas geográficas digitais eficientes. 
Alguns conceitos a respeito de Sensoriamento Remoto e de imagens geradas especificamente por sensores orbitais, pois uma das maiores funcionalidades do SPRING está no tratamento destas imagens, através de funções de realce e classificação.

Sintetizando, novos métodos de tratamentos orbitais tem sido desenvolvidos para avaliações sobre a dinâmica de uso e cobertura da terra, de "Analise de Vetor de mudanças", baseada em vetores em vetores espectrais e respectiva magnitude, definida por liminares pré-definidos (LORENA, 2001). Produtos-sensores baseados em dados de radar, de bandas $C, X, L$ e $P$, vêm sendo especificadamente investigados para o mapeamento, inventário e monitoramento florestal, com experiências, promissoras (FREITAS, 1999), que podem complementar a falta de informações em áreas onde há intensa e periódica cobertura de nuvens, nas quais as imagens ópticas não conseguem suprir com dados temporais primários.

As imagens de sensoriamento, por suas características espectral, temporal e espacial, são ferramentas efetivas de monitoramento dos recursos ambientais.

\section{2- Origem e Evolução do Sensoriamento Remoto}

A origem do sensoriamento remoto está ligada às experiências de Newton (1672) que constatou que um raio luminoso (luz branca), ao atravessar um prisma, desdobrava-se num feixe colorido - um espectro de cores.

Desde então os cientistas foram ampliando os seus estudos a respeito de tão fascinante matéria. Verificaram que a luz branca era uma síntese de diferentes tipos de luz, uma espécie de vibração composta, basicamente, de muitas vibrações diferentes. Prosseguindo, descobriram ainda que cada cor decomposta no espectro correspondia a uma temperatura diferente, e que a luz vermelha incidindo sobre um corpo, aquecia-o mais do que a violeta.

Além do vermelho visível, existem radiações invisíveis para os olhos, que passaram a ser ondas, raios ou ainda radiações infravermelhas. Logo depois, uma experiência de Titter revelou outro tipo de radiação: a ultravioleta. Sempre avançando em seus experimentos os cientistas conseguiram provar que a onda de 
luz era uma onda eletromagnética, mostrando que a luz visível é apenas uma das muitas diferentes espécies de ondas eletromagnéticas.

Alguns autores colocam a origem do Sensoriamento Remoto ligada ao desenvolvimento de sensores fotográficos, quando as fotografias aéreas eram tiradas por balões.

Fica evidente que o Sensoriamento Remoto é fruto de um esforço multidisciplinar que envolveu e envolve avanços na física, na físico-química, na química, nas biociências e geociências, na computação, na mecânica, etc.

\section{3- Definição de Sensoriamento Remoto}

Uma definição para sensoriamento remoto pode ser: "É a utilização de sensores para aquisição de informações sobre objetos ou fenômenos sem que haja contato direto entre eles."

- Sensores: são equipamentos capazes de coletar energia proveniente do objeto, convertê-la em sinal passível de ser registrado e apresentá-lo em forma adequada à extração de informações.

- Energia: na grande maioria das vezes refere-se a energia eletromagnética ou radiação eletromagnética.

Um conceito mais específico pode ser: "É o conjunto das atividades relacionadas com a aquisição e a análise de dados de sensores remotos", onde:

- Sensores Remotos: sistemas fotográficos ou óptico-eletrônicos capazes de detectar e registrar, sob a forma de imagens ou não, o fluxo de energia radiante refletido ou emitido por objetos distantes.

Um fluxo de radiação eletromagnética ao se propagar pelo espaço pode interagir com superfícies ou objetos, sendo por estes refletido, absorvido e mesmo reemitido. As variações que essas interações produzem no fluxo considerado, dependem fortemente das propriedades físico-químicas dos elementos na superfície. 
Tudo na natureza está em constante vibração, emitindo ou modificando ondas eletromagnéticas (energia) e apresentando "perturbações" dos campos magnéticos e gravimétricos da Terra. Todos os instrumentos que captam e transformam essa energia poderiam ser classificados como sensores: rádio, televisão, máquina fotográfica, etc.

Durante a fase de aquisição de dados pelos sensores, podemos distinguir os seguintes elementos básicos: energia radiante, fonte de radiação, objeto (alvo), trajetória e sensor (sistema de imageamento óptico e detector). A figura a seguir apresenta estes elementos e exemplifica os vários caminhos que a radiação eletromagnética pode tomar antes de atingir o sistema sensor.

Uma câmara fotográfica com flash poderia ser tomado como exemplo de um sistema sensor: "quando o sistema da câmara é ativado, o flash é acionado e emite radiação. A radiação flui para o alvo e é refletida deste para o sistema óptico da câmara. Então, a radiação refletida é focalizada sobre o plano do filme, que constitui um detector fotoquímico de radiação. Uma imagem latente do padrão de radiação é formada no filme e depois desenvolvida quimicamente" (Figura 5).

Figura 5: Trajetórias da Radiação.

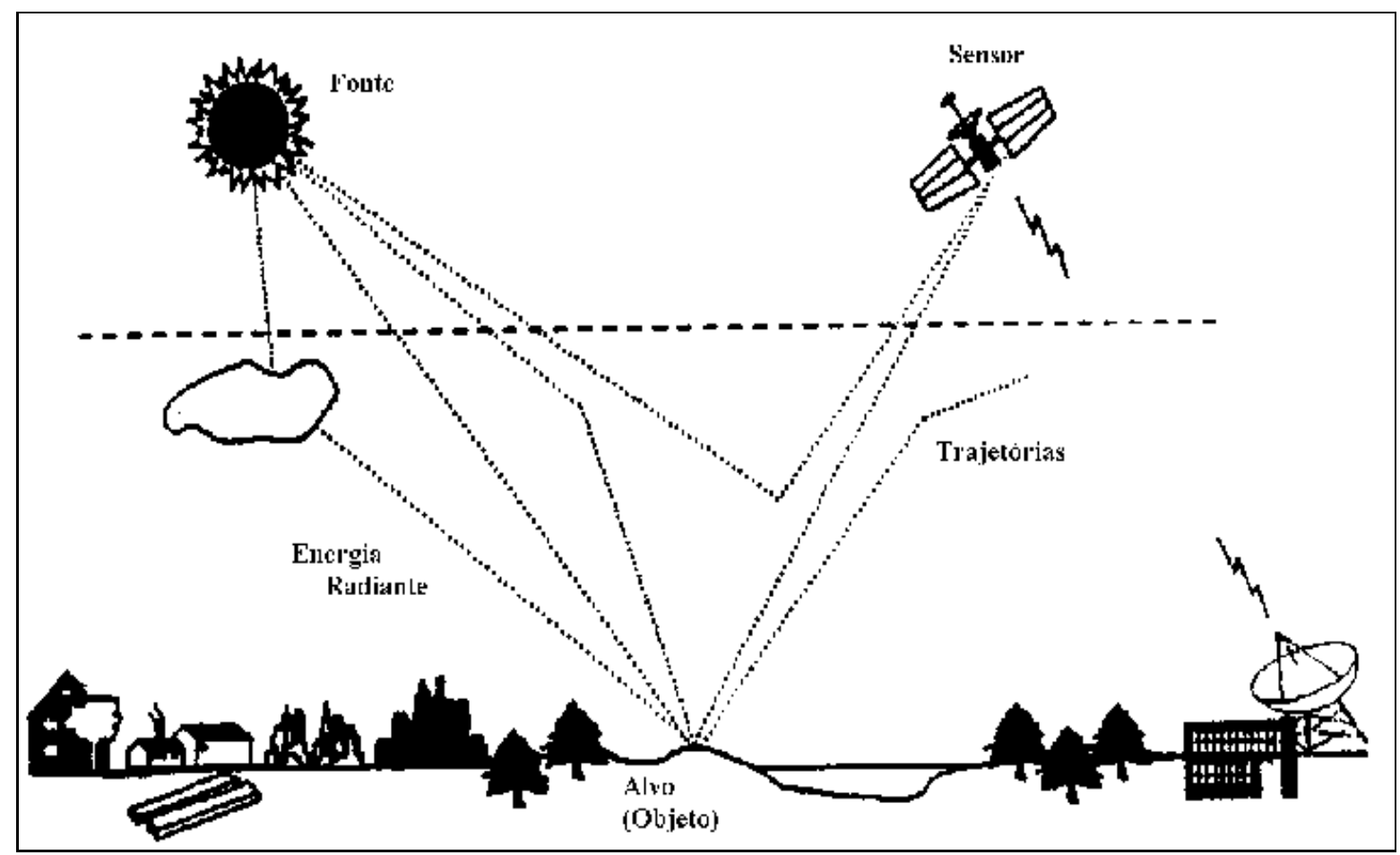

Fonte: INPE 
Sempre que se realiza trabalho, algum tipo de energia deve ser transferida de um corpo a outro, ou de um local para outro no espaço. De todas as possíveis formas de energia, uma de especial importância ao Sensoriamento Remoto, e a única que não necessita de um meio material para se propagar é a energia radiante ou energia eletromagnética. O exemplo de energia radiante mais familiar e de maior importância é a energia solar, que se propaga pelo espaço vazio desde o Sol até a Terra. 


\section{Capítulo II - Descrição da Metodologia da Pesquisa}

Esta monografia é fundamentada em uma pesquisa conceitual comparativa, mostrando a importância do geoprocessamento como auxílio aos profissionais do ecoturismo. Tendo como base a abordagem qualitativa.

Será realizada com o objetivo de observar, registrar e sistematizar os conceitos bibliográficos coletados, possibilitando, desta forma, uma aproximação maior da realidade que envolve a atividade ecoturística e a ferramenta geoprocessamental.

A coleta dos dados secundários ocorreu em fontes bibliográficas e documentais, como: livros, artigos, estudos teóricos, revistas científicas, periódicos, internet e publicações de pesquisadores, empresas, instituições e órgãos governamentais como do Instituto Brasileiro do Meio Ambiente e dos Recursos Naturais Renováveis (IBAMA)/Ministério do Meio Ambiente (MMA), Instituto Nacional de Pesquisas Espaciais (INPE), Instituto Brasileiro de Geografia e Estatistica (IBGE), Conselho Nacional de Desenvolvimento Científico e Tecnológico (CNPq)/Ministério da Ciência e Tecnologia (MCT) e Instituto Brasileiro de Turismo (EMBRATUR), no período de outubro de 2002 á maio de 2003. 


\section{Capítulo III - Resultados da Pesquisa}

Este trabalho fez uma comparação de conceitos de geoprocessamento destacando seus procedimentos e sua evolução, bem como a sua contribuição para a implantação do ecoturismo. Citou o desenvolvimento sustentável através do ecoturismo no Brasil, já que o mesmo tem o objetivo de incentivar a conservação e a utilização harmoniosa do patrimônio natural e cultural, além de estimular a geração de renda e a qualidade de vida das populações envolvidas.

$\mathrm{Na}$ pesquisa constatou-se em vários estudos de casos (estudos de cases) que $\mathrm{o}$ avanço da tecnologia de sensoriamento remoto, por intermédio dos variados produtos sensores e dos procedimentos metodológicos de tratamento de dados, aliados a sistemas de informação geográfica têm propiciado a operacionalização desse ferramental nas estimativas e na análise da distribuição espacial dos desflorestamentos da região amazônica. Esse processo é dinâmico e interativo.

Outro exemplo que deu certo é o Monitor de Ecoturismo em Resende - RJ. Um projeto ambiental e sócio-educativo, desenvolvido pela Prefeitura através da Secretaria Municipal do Meio Ambiente. Os seus principais objetivos são: a realização de um levantamento sobre as potencialidades e os problemas existentes em nossas localidades turísticas; o monitoramento dos impactos ambientais causados pelo turismo; a sensibilização da sociedade para a questão ambiental e a promoção do verdadeiro Ecoturismo. O projeto conta com a participação de entidades como o Grupo Excursionista Agulhas Negras (GEAN), o Grupo Ecológico de Engenheiro Passos (GEEP) e o Centro de Referência de Educação Ambiental de Resende (CREAR), além do Departamento de Turismo da Secretaria Municipal de Indústria, Comércio e Turismo de Resende.

Também foi constatado que a Fundação Estadual do Meio Ambiente (FEMA), 
por intermédio da Diretoria de Recursos Florestais, desenvolveu e está implantando um sistema de controle para conter desmatamentos ilegais, em propriedades rurais de Mato Grosso, e regularizar as atividades agropecuárias, em consonância com a legislação ambiental, visando ao uso correto do espaço produtivo, à conservação dos recursos florestais e à manutenção da biodiversidade em seu território. A FEMA é instituição publica criada pelo artigo $8^{\circ}$ da Lei 5.218 de 23 de dezembro de 1987 , como órgão executor da política Estadual de Meio Ambiente.

Nos últimos anos, foram geradas várias estimativas de áreas desflorestadas para o estado do Acre, cada uma objetivando sua importância. Dados do INPE fornecem taxas anuais de desflorestamento para todo os estados. Dados da FUNTAC e do IBAMA localizam desflorestamento, em nível de pequenas áreas, para o ano de 1996. O IBAMA também estima taxas de desflorestamento em Unidades de Conservação. Para Ter plena utilização desses dados, necessita-se intercalibração de métodos.

Um exemplo do desafio dessa intercalibração é o ano de 1996. Pode-se comparar as três fontes de dados em porcentagem das áreas desflorestadas do estado do Acre: INPE 9,0\%, FUNTAC 7,4 e IBAMA 5,0\%. Aparentemente pequenas, as diferenças nos índices são significativas. Por exemplo, a diferença de 1,6\% (INPE/FUNTAC), representa para o Acre uma área de $2.500 \mathrm{~km}^{2}$. A taxa média de desflorestamento indicada pelo INPE no Acre é de $600 \mathrm{~km}^{2} / \mathrm{ano}$, para o período de 1978 a 1999. Ou seja, a pequena diferença de 1,6\% seria equivalente a quatro anos de desflorestamento para o estado.

Nos trabalhos citados, foram envolvidos mais de trinta técnicos de diversas áreas, incluindo profissionais da STCP, das contratantes CVRD e MRN e IBAMA. Os trabalhos foram iniciados com um amplo e detalhado levantamento bibliográfico, seguido pelo levantamento de campo, que foi realizado com o objetivo de avaliar, in loco, as condições ambientais das áreas de estudo. As informações coletadas e geradas foram integradas em um banco de dados. O SIG da ESRI, fornecido pela GEMPI - Gestão Empresarial \& Informática Ltda., foi a ferramenta utilizada para a obtenção da base cartográfica, a análise e integração dos dados, a geração de novos mapas, temáticos e de vulnerabilidade, e para a elaboração do zoneamento, dos programas de manejo e das normas de conduta das Unidades de Conservação. 
As atividades descritas anteriormente alimentam uma base de dados que dá origem a uma série de informações, mostrando a importância do Geoprocessamento no Ecoturismo, transformando o Turismo meramente contemplativo em algo prazeroso e participativo. 


\section{Capítulo IV - Discussão dos Resultados da Pesquisa}

Baseando-se nos conceitos literários estudados, ratifica-se que a associação do geoprocessamento ao ecoturismo é o que faltava para o desenvolvimento e sustentabilidade do turismo.

Monitorar continuamente, desmatamentos e queimadas por meio de procedimentos que tratem as imagens de forma analógica ou digital, é plenamente possível se for levado em conta o interesse em níveis de informação global, regional e mesmo local. A diferenciação das técnicas no trato com as mesmas imagens de satélite, sejam as mais simplistas, que muitas vezes atendem objetivos de rápida fiscalização e controle, sejam as mais sofisticadas do ponto de vista científico, atendem plenamente as intrínsecas finalidades propostas.

Além dos exemplos aplicativos mostrados no estudo de cases, observa-se que a tecnologia necessária para se obter monitoramento em tempo real das regiões de potencial ecoturístico com o intuito de se observar e detectar "ecoturistas" perdidos, riscos causados por fenômenos naturais (desmoronamentos, enchentes, trombas d'água, incêndios etc) bem como atividades antrópicas como queimadas, desmatamentos e outros fatos que possam gerar prejuízos ao empreendimento ecoturístico como todo e ao meio ambiente é o geoprocessamento. Assim se houver monitoramento em tempo real e for detectado sinais de queimadas e incêndios ainda no início do procedimento, sem o devido aviso prévio, poderia ser acionadas as autoridades responsáveis para evitar maiores danos.

No Brasil a diminuição dos índices de desmatamento é uma prioridade do governo que tem investido no aperfeiçoamento de políticas de prevenção, monitoramento, licenciamento e fiscalização do desmatamento e queimadas, com incentivos para atividades econômicas sustentáveis. 
Nos anos recentes, o sensoriamento remoto e os SIG tem se revelado cada vez mais como ferramentas de alta potencialidade, na aplicação efetiva de tecnologias pertinentes como o geoprocessamento, que tem auxiliado no planejamento e empreendimentos ecoturísticos. 


\section{CONSIDERAÇÕES FINAIS}

O sistema apresentado de manipulação georreferenciada de dados turísticos é uma ferramenta de suma importância na atualidade no que tange ao desenvolvimento econômico de determinada região.

Nesse sentido, poderá ser desenvolvida uma política de gestão ambiental articulada à um planejamento do geoprocessamento, integrado ao ecoturismo. Estes projetos elaborados contam com a participação da comunidade na decisão de forma de utilização dos espaços e da potencialidade, empregando meios adequados para fiscalizar e avaliar a situação do ambiente e investigando as suas evoluções e tendências, é possível com o auxílio do geoprocessamento encontrar os caminhos para o uso e atendimentos das necessidades atuais.

O sistema de informação permite uma georreferência rápida, com dados préselecionados por temas, que gera novas informações concisas. Esta concepção de sistema de informação aplicada ao turismo já se faz realidade nos Estados Unidos e em vários países europeus onde há uma maior utilização da tecnologia de geoprocessamento.

A metodologia empregada mostrou-se em parte eficiente. Foi possível perceber que o geoprocessamento pode propiciar ao ecoturismo as ferramentas para observação e monitoramento de regiões. O GIS é determinante para o bom resultado no planejamento das Unidades de Conservação, devido a rapidez, precisão e confiança nas informações geradas e pelo potencial de uso de suas ferramentas de potencial ecoturístico, bem como identificar novos pólos de atividades do segmento do turístico.

Conclui-se que o ecoturismo é uma modalidade do turismo de crescimento acentuado, podendo se transformar numa solução para a degradação do meio ambiente, aliado ao geoprocessamento. Sabe-se porém, que são necessário estudos voltados para analisar os problemas de infra-estruturas que dificultam a 
implantação do setor no Brasil, analisar a oferta e a demanda turística, além de conhecer os produtos turísticos, e informações referentes ao potencial do nosso meio ambiente para desencadear projetos na área ecológica.

Em síntese a finalidade desta monografia é entre outras mostrar a eficácia e eficiência do ecoturismo aliado ao geoprocessamento, apresentando conceitos que auxiliem profissionais do ecoturismo e áreas correlatas, a utilizar SR, SIG, GPS, como mais uma estratégia e ferramenta para elaboração de empreendimentos e atividades ecoturísticas bem como para auxiliar o homem em favor da natureza. 


\section{REFERÊNCIAS BIBLIOGRÁFICAS}

- Planejamento Ambiental e Sistemas de Informações Geográficas Caderno de Informações Georreferenciadas. Campinas - SP: IC/UNICAMP v. 1, n.2, 1997 (Home Page Universidade de Campinas, disponível em <http://www.cpa.unicamp.br/revista/cigv1n2a2.html>.

ARONOFF, S. Geographic Information System: A Manegement Perspective. Otawa, WDI Publications, 1989.

BAKER, C. P. \& PANCIERA, E.C. 1990. A geographic information system for groundwater protection planning. Journal of Soil and Water Conservation, P.-248.

BALL, G.L. 1994. Ecosystem modeling with GIS. Environmental Management, 18(3): P. 349.

BARROS II, S.M., 1997. Turismo e Unidades de Conservação no Brasil. Cong. Bras. de U.C.. Anais Vol. I Conferências, Palestras, Resumos, Workshops. IAP, Univ. Livre do Meio Amb.. Curitiba - PR

BRASIL, MMA, IBAMA, DIREC. Roteiro metodológico para planejamento de unidades de conservação de uso indireto. Rascunho para discussão. Brasília, 1996. P. 66, Mimeo.

BRASIL. CONAMA. Resoluções do Conselho Nacional do Meio Ambiente: pesquisa, organização, remissão, comentários e revisão de Waldir de Deus Pinto e Marília de Almeida. Brasília: W.D. Ambiental, 1999. P. 932.

BRASIL. IBAMA. Possibilidades alternativas para o manejo e o gerenciamento das unidades de conservação. PNMA. Brasília, 1993. P.115. Mimeo.

BURROUGH, P. A.; MCDONNELL, R.A. Principles of geographical information systems. Oxford, Oxford University Press, 1998.

CÂMARA, G.; SOUZA, R.C.M.; FREITAS, U.M.; GARRIDO, J.C.P. "SPRING: Integrating Remote Sensing and GIS with Object-Oriented Data Modelling". Computers and Graphics, vol.15, n.6, July 1996, pp.13-22.

CARNEIRO, C. M. R. Curso Básico de Sensoriamento Remoto, Brasília-DF, 1980, P.198 . (PNUD/FAO/BRA/78 - Série Técnica ํo 6).

COWEN, D.J. GIS versus CAD versus DBMS: what are the differences. Photogrammetric Engineering and Remote Sensing, P1555. 1988.

DAJOZ, R. Ecologia Geral. 2nd ed., Vozes, Petrópolis, e Universidade de São Paulo., São Paulo. P.472. 1973. 
DENÈGRE, J. 1994. Technological progress in geographical research: recent developments in satellite remote sensing and geographical information systems. Mapping Sciences and Remote Sensing, P.55.

DIAS, Genebaldo Freire. Populações Marginais em Ecossistemas Urbanos. Brasília. IBMARNR, 1989.

DUARTE, Paulo Araújo. Cartografia temática. Editora da Universidade Federal de Santa Catarina. Florianópolis. 1991. P.154.

FREITAS, C.C.; SANT'ANNA, S. 1 S.; RENNO, C. D. The use of JERS - 1 and Radarsat images of land use classification in the Amazon region - In: Intenational Geocience and Remote Sensing Symposium. IGARSS'99: Remote Sensing of the System Earth: A Challenge for the 21 st Century. Hamburg, Germany, 28 june - 2 july, 1999. Proceedings. [CD-ROM].

HENDRIX, W. G.; FABOS, J.G. \& PRICE, J.E. 1988. An ecological approach to landscape planning using geographic information system technology. Landscape and Urban Planning, P.225.

INPE. Fundamentos de Geoprocessamento./Spring. Disponível na Internet em: <http://www.dpi.inpe.br/spring.> Acesso em: 4.jan.2003.

INPE. Técnicas de Apresentação de Dados em Geoprocessamento./ Cap.II/ Conceitos básicos/ Sistema de informações Geográficas /p. 1. Disponível na Internet em: <http://www.dpi.inpe.br/teses/lauro/cap2.pdf> Acesso em: 4.jan.2003.

LEES, B.G. \& RITMAN, K. 1991. Decision-tree and rule-induction approach to integration of remotely sensed and GIS data in mapping vegetation in disturbed or hilly environments. Environmental Management, P.831.

LEOPOLD, A. A sand county almanac. Oxford Univ. Press, P. 239. 1949.

LORENA, R. B. Evolução do uso da terra em porção da Amazônia Ocidental (Acre), com uso de técnicas de detecção de mudanças. Instituto Nacional de Pesquisa Especiais - INPE, São José dos Campos, 2001. Dissertação de Mestrado em Sensoriamento Remoto. P. 92

LORINI, Maria Lucia., PERSSON, Vanessa Guerra., SILVA, Jorge Xavier da. Construindo capacitação profissional em Geoprocessamento: o exemplo do programa CEGEOP. Volume 6 Número 2 Abr/Mai/Jun 2002. Revista Geonotas. Departamento de Geografia - Universidade Estadual de Maringá. Disponível na Internet em: < http://www.dge.uem.br//geonotas/vol6-2/silva.shtml>. Acesso em : 1.fev.2003.

MMA. Atlas - Os Ecossistemas Brasileiros e os Principais Macrovetores de Desenvolvimento/Ecossistemas. Disponível na Internet em: <http://www.mma.gov.br/port/sbf/index.cfm> Acesso em 1.fev.2003.

MMA. Histórico de áreas protegidas. Disponível na Internet em: <http://www.mma.gov.br/port/sbf/dap/apbhist.html. Acesso em: 2.fev.2003. 
NCGIA, The Research Plan for the NCGIA, International Journal of Geographic Information Systems, P.136, 1989.

PAREDES, Evaristo Atencio. Sistema de Informação Geográfica - SIG: Geoprocessamento, princípios e aplicações. SAO PAULO : ERICA, 1994. P.675 Dissertação de Mestrado.

QUINTÃO, A.., S., F., 1990. Ecoturismo: uma Alternativa do novo modelo de desenvolvimento. Ver. Brasil Florestal, $n^{\circ}$ 69, 1ํs semestre. IBAMA, Brasília-DF. 1990. P. 38.

ROCHA, A. M. A. Levantamento da Vegetação Natural e do uso da terra, utilizando imagens TM/Landsat. Boletim de Pesquisa, P. 124, Embrapa/CPATU, Belém. 2000.

RODRIGUES, M. Introdução ao Geoprocessamento. Simpósio Brasileiro de Geoprocessamento. Atas., Escola Politécnica. USP. São Paulo, pp1-26. 1990.

SAITO, C. H. Considerações Teórica-metodológicas acerca do potencial heurísticos no uso de Sistema Geográfico integrado a banco de dados relacional em diagnóstico de risco à saúde populacional devido a poluição industrial. Revista Brasileira de Ecologia ano 1 no 2: 15-21. 1995.

TEIXEIRA, A., MORETTI, E. \& CHRISTOFOLETTI, A., 1992. Introdução aos Sistemas de Informações Geográficas. Rio Claro. WEARING, Stephen. Ecoturismo impactos potencialidades e possibilidades. Manole. $1 \mathrm{Ed}$.

XAVIER, de Silva I., 1992. Geoprocessamento e Análise Ambiental. Revista Bras. de Geografia P.47. 


\section{GLOSSÁRIO}

- Algoritmo: Em programação, conjunto de operações necessárias à solução de um problema.

- Aplicativo: Termo usado para um programa de computador (software), criado para atender as necessidades específicas de um determinado usuário.

- Atributo: Tipo de dado não gráfico que descreve as entidades representadas por elementos gráficos. Termo usado para citar os tipos de dados não gráficos e, normalmente alfanuméricos, ligados a um mapa.

- Banco de dados: Conjunto de dados organizado de maneira lógica, ou seja, numa seqüência que permite acesso rápido e simples.

- Banco de dados relacional: Série de arquivos ou tabelas que podem ser conectadas ou inter-relacionadas através de um item ou informação comum a dois ou mais desses arquivos.

- Banda: Um dos níveis de uma imagem multiespectral, representado por valores refletidos por valores refletidos de luz ou calor de uma faixa específica do espectro eletromagnético.

- Bússola: Instrumento que contém agulha magnética, móvel em torno de um eixo que passa pelo seu centro de gravidade, montada em caixa com limbo graduado e usado para orientação.

- Cadastro: Inventário ou levantamento de todos os bens e posses de uma determinada área, com município, Estado, País e destinado à determinação rigorosa do parcelamento da propriedade territorial e do uso do solo. Pode também abranger informações sócio-econômicas.

- Cartografia: 1- Ramo da ciência que trata da elaboração de mapas, proporciona subsídios para a análise e interpretação de mapas, tabelas e outros recursos gráficos. 2- Conjunto de operações científicas, artísticas e técnicas produzidas a partir de resultados de observações diretas ou de exposições de documentos.

- Coordenadas: Valores lineares e/ou angulares que indicam a posição ocupada por um ponto num sistema de referência qualquer.

- Dado: 1- Qualquer grandeza numérica ou geométrica, ou conjunto de tais quantidades, que pode servir como referência ou base para cálculo de outras grandezas. 2- Representação de fatos, conceitos e instruções apropriadas para o processamento por meios humanos ou automáticos. 
- Dados vetoriais: Conjunto de vetores que permitem formar pontos, linhas ou linhas fechadas (poligonais).

- dbMapa: Software que permite a junção de bancos de dados relacionais a arquivos gráficos MaxiCAD.

- Digitalização: Processo de captura de informações através do uso de mesas digitalizadoras.

- Fotografia infravermelha colorida: ver fotogrametria.

- Fotogrametria: Ciência da elaboração de cartas, mediante fotografias aéreas, utilizando-se aparelhos e métodos estereoscópicos. O mesmo que Aerofogrametria. 2- Técnica de determinação das curvas de nível, nos levantamentos cartográficos, por meio de pares de fotografias.

- Fotoplotter: Dispositivo plotador de gráficos, no caso imagens sobre papel sensível, ou filme.

- Fototriangulação: Processo da extensão do controle horizontal ou vertical, por meio do qual as medições de ângulo ou de distâncias em fotografias estereoscópica têm relação com uma solução espacial, usando-se os princípios da perspectiva das fotografias.

- Função proximidade: Função de CADs que analisa coordenadas de um ponto inserido em um desenho. Pode substituí-las pelas coordenadas formadoras de outro objeto, desde que aquele ponto se encontre dentro de um circuito limite com raio definido pelo usuário.

- Fuso UTM: Zona de projeção delimitada por dois meridianos cuja longitude difere de 6 graus e por dois paralelos de latitude 80 graus, Norte e Sul.

- Geodésia: 1- Ciência que procura definir e situar as características naturais e físicas de grandes porções da superfície terrestre; 2- Ciência que busca a detrminação da forma e das dimensões da Terra.

- Geodésia Tridimensional: A que se caracteriza pela eliminação do uso de superfícies de referência e intermediárias utilizadas nos métodos geodésicos clássicos e modernos, e o emprego de um sistema triortogonal de coordenadas com origem no centro de massa da terra.

- Geofísica: Ramo da física experimental que se preocupa em determinar a estrutura, a composição e o desenvolvimento da Terra, inclusive a atmosfera e a hidrosfera.

- Geografia: Ciência que estuda a distribuição dos fenômenos físicos, biológicos e humanos na superfície da Terra, as causas dessa distribuição e as relações locais de tais fenômenos.

- Geóide: Superfície equipotencial do campo gravimétrico da Terra, coincidindo com o nível médio inalterado do mar, e que se estende por todos os continentes, 
sem interrupção. A direção da força da aceleração da gravidade é perpendicular ao geóide é a sua superfície de referência para as observações astronômicas e para o nive lamento geodésico.

- Geomorfologia: Ciência que estuda as formas de relevo, tendo em vista a origem, da estrutura, natureza das rochas, o clima da região e as diferentes forças endógenas e exógenas que, de modo geral, entram como fatores modificadores do relevo do relevo terrestre.

- Geoprocessamento: Conjunto de tecnologias de coleta, tratamento, desenvolvimento e uso de informações georreferenciadas.

- GIS: Geographic Information System / Sistema de Informação Geográfica (SIG): Sistema de computador composto de hardware, software, dados e procedimentos, construído para permitir a captura, gerenciamento, análise, manipulação, modelamento e exibição de dados referenciados geograficamente para solucionar, planejar, gerenciar problemas.

- Glossário: Dicionário de termos técnicos, científicos, poéticos, etc.

- Hardware: Conjunto formado pelos equipamentos de processamento de dados e seus componentes como monitor, mouse, mesa digitalizadora, CPU, disco rígido, impressora, plotter, scanner, modem etc.

- Hidrografia: 1- Ciência que se ocupa da medida e descrições das características físicas dos oceanos, mares, lagos, e rios, bem como das suas áreas costeiras contíguas, com a finalidade em geral, de navegação. 2- Representação cartográfica dos elementos hidrográficos permanentes ou temporários.

- Imagem: Registro permanente em material fotográfico de acidentes naturais, artificiais, objetos e atividades, obtido por sensores como o infravermelho pancromático e o radar de alta resolução.

- Imagem de radar: Combinação do processo fotográfico e de técnicas de radar. Impulsos elétricos são emitidos em direções predeterminadas, e os raios refletidos, ou devolvidas, são utilizados para fornecer imagens em tubos de raios catódicos. As imagens são, depois, obtidas da informação exposta nos tubos.

- Imagem de satélite: Imagem captada por um sensor a bordo de um satélite artificial, codificada e transmitida para uma estação rastreadora na Terra (imagem raster).

- Imagem multiespectral: Imagem de múltiplas bandas, isto é, obtida por vários sensores que detectam a energia em bandas de diferentes comprimentos de onda.

- Informação: Conjunto de dados que possuem significado próprio.

- Informação georreferenciada: Dados alfanuméricos geograficamente referenciados às informações gráficas de um mapa. 
- Informática: Ciência do tratamento racional e automático de informação considerando-se esta como base do conhecimento e comunicação.

- Instrução ou comando: Em programação, é a sentença que especifica uma operação e os valores ou posições de seus operandos como a soma de dois números.

- Inteligência artificial: Campo da informática que busca aperfeiçoar computadores, dotando-se de características peculiares da inteligência humana, como a capacidade de entender a linguagem natural e simular o raciocínio em condições de incerteza.

- Interface: Neologismo para interação ou ligação. Ex. interface cliente-fornecedor e interface com programas e arquivos. Interface é, em informática, um circuito eletrônico que controla a interligação entre dois dispositivos de hardware e os ajuda a trocar dados de maneira confiável.

- Interface com o usuário: Características de um programa ou computador que determinam a forma como interage com os usuários.

- Landsat: Um dos programas americanos de imageamento da superfície terrestre por satélites, iniciado pela NASA em meados dos anos 70. Também usado para designar um ou mais satélites do programa (Landsat 4 e 5) e os dados de imagens por eles enviados.

- Layers: Dados cartográficos organizados em camadas.

- Mapa digital: Mapa produzido e armazenado em meio magnético.

- Mapa ou Carta: Representação gráfica analógica ou digital, geralmente em uma superfície plana e em determinada escala, das características naturais e artificiais da superfície ou da sub-superfície terrestre. Os acidentes são representados dentro da mais rigorosa localização possível, relacionados em geral, há um sistema de referência coordenadas.

- Mapa temático: Mapa relacionado a um determinado tópico, tema ou assunto em estudo. Mapas temáticos ou mapas-síntese enfatizam tópicos, tal como vegetação, geologia ou cadastro de propriedade.

- MaxiCAD: Software utilizado principalmente em aplicações de mapeamento por computador.

- MaxiDATA: Empresa constituída pelos funcionários responsáveis pelo setor de informática da empresa de aerolevantamento AeroSul; criaram um sistema para automatização de processos cartográficos.

- Mesa Digitalizadora: Mesa dotada de uma malha eletrônica e um cursor para entrada de informações, que utiliza caracteres numéricos para representar dados contínuos.

- MMS: Sistemas imageadores multiespectrais. 
- Modelos Numéricos ou modelos digitais: Modelos formalizados por meio de expressões matemáticas e lógicas. Em Cartografia servem para modelar a superfície do terreno.

- Moms Ers: Um dos programas americanos de imageamento da superfície terrestre por satélites.

- Monitor: 1- Dispositivo destinado à observação; 2- Dispositivo para saída (visualização) de informações, o mesmo que terminal de vídeo; 3- Aquele que auxilia o professor nas aulas.

- Monitoramento:ver monitor.

- Multiespectral: ver Imagem multiespectral.

- ORACLE: Banco de dados cliente-servidor.

- Orientação: O ângulo horizontal de um determinado ponto medido na direção dos ponteiros do relógio, a partir de um ponto de referência, para um segundo ponto. O mesmo que ângulo de direção.

- Pixels: Abreviatura de "picture elements", elementos formadores das estruturas raster, definidos por linhas verticais e horizontais espaçadas regularmente.

- Plotter eletrostático: Traçador de gráficos que opera pelos princípios básicos da eletricidade estática, ou seja, o desenho fixa-se no papel aproveitando a propriedade de atração entre cargas opostas do papel e da tinta.

- Precisão: Exatidão dos cálculos ou da gama de valores que expressam uma quantidade.

- Projeção: Maneira pela qual a superfície da Terra é representada em superfícies bi-dimensionais, procurando-se minimizar a distorção em área, distância e direção.

- Projeção cartográfica: Conjunto de métodos usados na representação da superfície terrestre, segundo o qual cada ponto da Terra corresponde a um ponto da carta e vice-versa.

- Radar: Técnica, ou equipamento, para localizar objetos móveis ou estacionários, medir-Ihes a velocidade, determinar-Ihes a forma e a natureza que utiliza a emissão de microondas moduladas e a detecção e análise do pulso refletido pelos objetos.

- Raster, Imagem Raster: Informações não simbolizadas por equações matemáticas e sim por células ou pixels.

- Resolução de imagem: Tamanho mínimo de detalhe que pode ser detectado na imagem.

- Resolução de tela ou resolução: Medida normalmente expressa em pontos por 
polegada (dpi - dots per inch). Define a nitidez horizontal e vertical das imagens geradas por um dispositivo de saída, com um monitor, um a impressora laser ou um plotter. Nos monitores, a resolução corresponde ao número de pixels exibidos na tela.

- Resolução do sistema de lentes (de câmara fotográfica): Capacidade que esse sistema possui de discriminar entre dois objetos bem definidos, ou seja, capacidade de mostrar detalhes, muito próximos entre si.

- Resolução espacial: Capacidade que o filme fotográfico, em combinação com o sistema de lentes e os filtros utilizados por uma câmara, tem de registrar diferentes pormenores do terreno.

- Resolução radiométrica ou Espectral: Medida da largura das faixas espectrais e da sensibilidade do sistema sensor (a bordo de um satélite) que distingue entre dois níveis de intensidade do sinal de retorno. Ex. resolução de $30 \mathrm{~m}$.

- Satélites artificiais: Dispositivos lançados no espaço que orbitam ao redor da Terra e transmitem informações diversas (ambientais, meteorológicas, de posicionamento).

- Scanerizar: ver scanner

- Scanner: Dispositivo ótico de varredura, que captura imagens e as transfere para um computador no formato raster.

- Seasat, Ers, Landsat: Satélite de Recursos Naturais

- Sensor: 1- Recurso técnico que aumenta os sentidos do homem (bússola, lente, termômetro, auto-falante...). 2- Dispositivo ou aparelho sensorial que capta e registra, sob a forma de imagem, a energia refletida ou emitida pela configuração do terreno, objetos e acontecimentos, incluindo os acidentes artificiais e os fenômenos físicos, incluindo os acidentes artificiais e os fenômenos físicos, bem como as atividades do homem. A energia pode ser nuclear, eletromagnética (com inclusão das partes visíveis e invisíveis do espectro), químico, biológica, térmica, mecânica, e, ainda, os ventos, os sonos e a vibração da terra.

- Sensoriamento remoto: Detecção e/ou identificação de um objeto sem que se tenha um sensor em contato direto com um objeto. Inclui análises por satélite e fotos aéreas. Registro da energia refletida ou emitida por objetos ou elementos da superfície terrestre ou de outros astros, por sensores localizados a grandes distâncias (geralmente no espaço).

- Série: Conjunto de folhas de um formato uniforme e na mesma escala com título e índice de referência, cobrindo uma região, um estado, um país, um continente ou um globo terrestre. Em geral usa-se abreviadamente, série.

- Servidor: Computador de folhas de um formato uniforme e na mesma escala com título e índice de referência, cobrindo uma região, um estado, um país um continente ou um globo terrestre. Em geral usa-se abreviadamente, série. 
- SGBD ou DBMS: Sistema de Gerenciamento de Banco de Dados

- SIG: Sistema de Informação Geográfica / Geographic Information System (GIS): Sistema de computador composto de hardware, software, dados e procedimentos, construído para permitir a captura, gerenciamento, análise, manipulação, modelamento e exibição de dados referenciados geograficamente para solucionar, planejar, gerenciar problemas.

- Sir: Um dos programas americanos de imageamento da superfície terrestre por satélites.

- Sistema Multiespectral: ver Imagem Multiespectral.

- Sistema multitarefa: Sistema com capacidade de multiprogramação ou de multiprocessamento. Executa de forma concorrente uma tarefa principal e uma ou mais subtarefas.

- Sistema operacional: Conjunto de programas que gerenciam as funções internas do computador e permitem que o usuário controle sua operação.

- Software: Conjunto de componentes lógicos que possibilitam o funcionamento dos componentes físicos do computador. Pode ser: Software básico: composto de programas de controle das funções básicas do computador. Software de aplicação: programas de solução.

- Spot: Sistema de satélites francês, usado para gerar imagens raster da terra.

- SPRING: Banco de Dados Geográfico do SIG

- Técnicas fotogramétricas: ver fotogrametria.

- Terminal: Dispositivo de entrada e saída, constituído de teclado e monitor, através do qual o usuário se comunica com o computador central de uma rede.

- Themes: Feições do mapa organizadas por temas.

- UTM: Universal Transverse Mercator. Sistema de coordenadas planas que circulam o globo baseado em 60 zonas de tendência, no sentido norte-sul, cada uma com 16 graus de largura de longitude.

- Vetor: Segmento de linha reta, com o tamanho normalmente representado pelos pares de coordenadas dos pontos extremos. Dados vetoriais referem-se a dados em forma tabular com uma dimensão. 